Check for updates

Cite this: J. Mater. Chem. B, 2021 9, 5221

Received 15th March 2021, Accepted 26th May 2021

DOI: 10.1039/d1tb00559f

rsc.li/materials-b

\section{Fabrication of nanoparticles for bone regeneration: new insight into applications of nanoemulsion technology}

\begin{abstract}
Barbara Kupikowska-Stobba (D) * and Mirosław Kasprzak
Introducing synthetic bone substitutes into the clinic was a major breakthrough in the regenerative medicine of bone. Despite many advantages of currently available bone implant materials such as biocompatiblity and osteoconductivity, they still suffer from relatively poor bioactivity, osteoinductivity and osteointegration. These properties can be effectively enhanced by functionalization of implant materials with nanoparticles such as osteoinductive hydroxyapatite nanocrystals, resembling inorganic part of the bone, or bioactive polymer nanoparticles providing sustained delivery of pro-osteogenic agents directly at implantation site. One of the most widespread techniques for fabrication of nanoparticles for bone regeneration applications is nanoemulsification. It allows manufacturing of nanoscale particles $(<100 \mathrm{~nm}$ ) that are injectable, 3D-printable, offer high surface-area-to-volume-ratio and minimal mass transport limitations. Nanoparticles obtained by this technique are of particular interest for biomedical engineering due to fabrication procedures requiring low surfactant concentrations, which translates into reduced risk of surfactant-related in vivo adverse effects and improved biocompatibility of the product. This review discusses nanoemulsion technology and its current uses in manufacturing of nanoparticles for bone regeneration applications. In the first section, we introduce basic concepts of nanoemulsification including nanoemulsion formation, properties and preparation methods. In the next sections, we focus on applications of nanoemulsions in fabrication of nanoparticles used for delivery of drugs/biomolecules facilitating osteogenesis and functionalization of bone implants with special emphasis on biomimetic hydroxyapatite nanoparticles, synthetic polymer nanoparticles loaded with bioactive compounds and bone-targeting nanoparticles. We also highlight key challenges in formulation of nanoparticles via nanoemulsification and outline potential further improvements in this field.
\end{abstract}

EUKASIEWICZ Research Network - Institute of Ceramics and Building Materials, Ceramic and Concrete Division in Warsaw, Department of Biomaterials, Postepu 9, 02-677, Warsaw, Poland.

E-mail: barbara.kupikowska-stobba@icimb.lukasiewicz.gov.pl

\section{Introduction}

Introducing synthetic bone substitutes into the clinic was a major breakthrough in the regenerative medicine of bone. ${ }^{1}$

Mirostaw Kasprzak, received his MSc degree in Food Technology and Human Nutrition from University of Life Sciences in Lublin, Poland and PhD degree in animal science from Aarhus University, Denmark (2013). Currently, he is the leader of the research project "Multifunctional biologically active composites for applications in regenerative medicine of bone" conducted in the Department of Biomaterials at LUKASIEWICZ Research Network - Institute of Ceramics and Building Materials in Warsaw, Poland. He has co-authored 13 publications in scientific journals and 1 monograph. His research interest lies in the development of multifunctional bone implants composed of hydroxyapatite and biodegradable polymers. synthesis and modification of hydroxyapatite with pro-osteogenic factors. 
Advances in the field of biomaterials have allowed development of bone implants that are biocompatible, bioresorbable $e^{2,3}$ and osteoconductive $^{4,5}$ (i.e. able to support bone growth on their surface). Despite these advantages, the vast majority of currently available implant materials suffer from poor bioactivity, ${ }^{4}$ osteoinductivity $^{6}$ (ability to induce osteogenesis) and osteointegration. ${ }^{7}$ Over the past few decades, many efforts have been devoted to improving properties of implant materials by their functionalization with nanoparticles such as osteoinductive hydroxyapatite nanocrystals resembling inorganic part of the bone or bioactive nanoparticles loaded with different types of drugs/biomolecules such as factors facilitating osteogenesis (e.g. bone morphogenetic proteins, BMPs, ${ }^{8-10}$ osteopontin, ${ }^{11}$ dexamethasone $\left.{ }^{12}\right)$, antimicrobial $\left(\mathrm{Ag}^{13}{ }^{13} \mathrm{CuO},{ }^{14} \mathrm{Se},{ }^{15}\right.$ curcumin, ${ }^{16-18}$ chlorhexidine ${ }^{19,20}$ ) or anti-inflammatory agents (e.g. curcumin, ${ }^{16-18,21}$ quercitrin $^{22,23}$ ) and drugs inhibiting bone resorption (e.g. bisphosphonates such as alendronate $\mathrm{e}^{24-26}$ ).

One of the most widespread and versatile methods for fabrication of nanoparticles is nanoemulsification. It relies on formation of dispersions of nanosized droplets by mixing a polar phase with a non-polar phase in the presence of a surfactant ${ }^{27}$ and allows manufacturing of very small particles $(<100 \mathrm{~nm})$ that are injectable, 3D-printable, offer high surface-area-to-volume-ratio and minimal mass transport limitations. Nanoparticles obtained by nanoemulsion technology have received particular attention in biomedical engineering due to fabrication procedures requiring lower surfactant concentrations (compared to other emulsifications methods i.e. macro- and microemulsification ${ }^{28}$ ) or no surfactant at all, translating into reduced risk of in vivo adverse effects associated with high surfactant levels (e.g. cytotoxicity $^{29,30}$ and mucosa irritation ${ }^{31}$ ) and improved biocompatibility of the final product. These qualities have contributed to the broad use of nanoparticles formulated via nanoemulsion technology in different fields of tissue engineering including bone, ${ }^{32-35}$ cartilage $^{36}$ neural $^{37}$ and cardiac ${ }^{37,38}$ tissue engineering. ${ }^{39,40}$

Among nanoparticles (NPs) fabricated via nanoemulsion technology hydroxyapatite NPs and drug-loaded synthetic polymer NPs have been the most extensively studied in the context of bone regeneration applications. Hydroxyapatite nanoparticles have been widely explored as fillers and strengths enhancers of orthopaedic and dental implants ${ }^{41-44}$ due to their excellent biocompatibility ${ }^{45,46}$ and well documented osteoconductive $^{47}$ and osteoinductive ${ }^{48-50}$ properties. When incorporated into implant material, they improve a number of properties crucial for its in vivo performance such as hydrophilicity, ${ }^{51}$ surface properties, ${ }^{52}$ mechanical resistance ${ }^{53-55}$ and osteoinductivity. ${ }^{56,57}$ Osteoinductivity of nano-hydroxyapatite is attributed to the size of its particles and their high resemblance to hydroxyapatite nanocrystals occurring in the natural bone. ${ }^{58-60}$ As a result, hydroxyapatite nanocrystals are better recognized by the host cells compared to their micron-sized counterparts ${ }^{61,62}$ and thus can more effectively stimulate cellular behaviors involved in osteogenesis such as osteogenic differentiation, cell adhesion, proliferation and migration. ${ }^{48}$

Synthetic polymer nanoparticles are probably the largest category of NPs used for bone regeneration applications. ${ }^{63}$
This type of NPs is typically made of biodegradable polymers such as poly(lactide-co-glycolide) (PLGA), poly(lactic acid) (PLA), poly( $\varepsilon$-caprolactone) (PCL) or polyethylene glycol (PEG) and are predominantly applied as delivery vehicles for pro-osteogenic agents (e.g. bone morphogenetic proteins, BMPs ${ }^{8-10}$ ) and drugs preventing bone resorption, ${ }^{24-26}$ implant-related infections or inflammation. ${ }^{16-18,21}$ Drug-loaded nanoparticles can provide controlled sustained drug release over extended periods of time $\mathrm{e}^{16,18,21,64}$ and can be easily introduced into bone defects (e.g. via injection), which may eliminate adverse side effects of drugs administered systemically and current therapeutic approaches to bone injuries based on supra-physiological doses of BMP-2. ${ }^{65}$

In this review, we discuss nanoemulsion technology and its current uses in manufacturing of nanoparticles for bone regeneration applications. In the first section, we introduce basic concepts of nanoemulsification including nanoemulsion formation, properties and preparation methods. In the next sections, we focus on applications of nanoemulsions in fabrication of nanoparticles used for delivery of drugs/biomolecules facilitating osteogenesis and functionalization of bone implants with special emphasis on biomimetic hydroxyapatite nanoparticles, synthetic polymer nanoparticles loaded with bioactive compounds and bone-targeting nanoparticles. We also highlight key challenges in formulation of nanoparticles via nanoemulsification and outline potential further improvements in this field.

\section{Nanoemulsion technology}

Nanoemulsions (also known as mini-emulsions) are heterogeneous systems, in which nanosized droplets $\left(<100 \mathrm{~nm}^{27}\right)$ of one immiscible liquid (the dispersed phase) are dispersed in another liquid (the continuous phase). Nanoemulsions are formed by mixing an oil (non-polar) phase with an aqueous (polar) phase in the presence of an emulsifier. First, the dispersed phase is broken up into larger droplets forming a macroemulsion (also called a coarse emulsion), which in the second step is broken up into nanodroplets. ${ }^{66}$ Deformation and breaking up of the droplets expands the interface between the phases, which significantly increases interfacial area and interfacial energy. For this reason, formation of nanoemulsions does not occur spontaneously and requires energy input. ${ }^{28}$ The role of emulsifier is to reduce the interfacial tension between the immiscible phases and lower the shear force needed to break up the droplets. ${ }^{67}$ At the same time, emulsifier molecules adsorbed to the surface of newly formed droplets impart a physical barrier between neighbouring droplets, which stabilizes them and prevents them from coalescing. ${ }^{28}$

The ability of emulsifiers to stabilize the droplets results from their amphiphilic structure. Emulsifier molecules are composed of a hydrophilic group (the head) and a hydrophobic domain (the tail). When added to an oil-in-water (o/w) emulsion (dispersion of oil droplets in an aqueous phase), emulsifier molecules spontaneously surround the oil droplets with their 

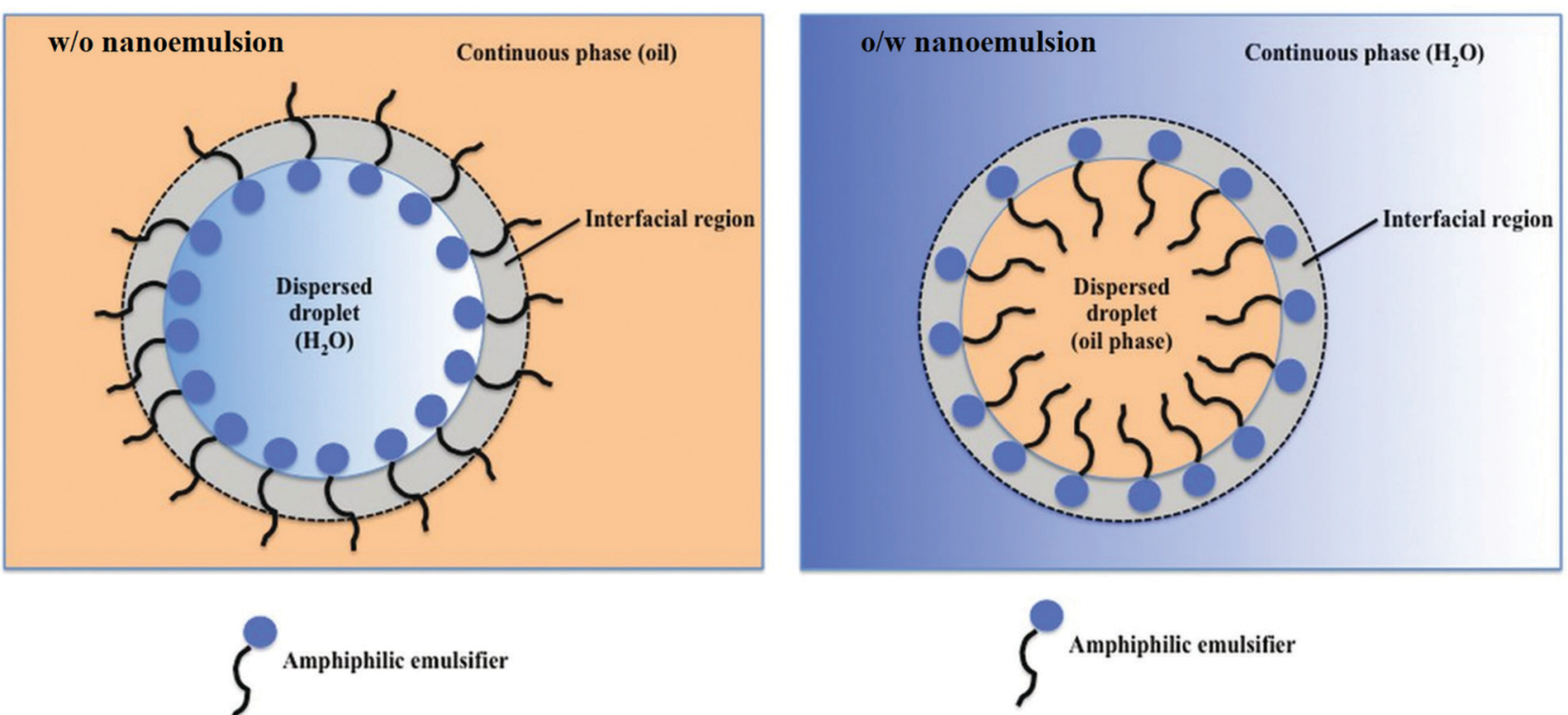

Fig. 1 Illustration of a regular (oil-in-water, o/w) and reverse (water-in-oil, w/o) nanoemulsion droplets stabilized with an amphiphilic emulsifier. W/o nanoemulsion (left): non-polar tails are directed towards the oil phase, whereas polar heads point to the center of water droplets. O/w nanoemulsion (right): amphiphilic emulsifier molecules spontaneously surround the oil droplets with their non-polar tails extending into the droplet, while their heads direct outwards, towards the continuous polar phase. Copyright(C2017 Scrivener Publishing LLC. Reproduced from ref. 69: https://doi.org/10.1002/ 9781119364221.ch6 with permission from Scrivener Publishing LLC.

non-polar tails extending into the droplet, while their heads direct outwards (towards the continuous phase) as depicted in Fig. 1. In the case of the reverse (water-in-oil, w/o) nanoemulsions (composed of water droplets dispersed in the oil phase), the orientation of emulsifier molecules is reversed: nonpolar tails are directed outwards (facing the oil phase), whereas polar heads point to the center of water droplets (Fig. 1). Oil-inwater emulsions are referred to as regular emulsions, ${ }^{68}$ whereas water-in-oil emulsions are called reverse or invert emulsions. When emulsion is further dispersed into another continuous phase, it is called a multiple emulsion or emulsified emulsion. An example of multiple emulsion is oil-water-oil (o/w/o) emulsion, which consists of small oil droplets dispersed in larger water droplets suspended in the continuous oil phase.

\section{Properties of nanoemulsions}

Nanoemulsions have several significant advantages over conventional emulsions (macroemulsions) containing droplets in the $0.1-5.0 \mu \mathrm{m}$ range ${ }^{70}$ and microemulsions containing droplets ranging in size from 10 to $100 \mathrm{~nm} .{ }^{71}$ First, nanoemulsions are much more kinetically stable than macroemulsions, i.e. they can resist phase separation for much longer periods of time. ${ }^{72}$ Increased kinetic stability of nanoemulsions is attributed to their very small droplet size, which prevents gravitation-driven phase separation processes such as droplet sedimentation and flocculation (a process where droplets group together, but do not merge, Fig. 2). Second, due to the droplet size significantly smaller than the wavelength of visible light $(380-700 \mathrm{~nm})$, nanoemulsion droplets scatter little light, making them appear transparent, as opposed to macroemulsions, which are usually opaque or turbid. ${ }^{73}$ This quality allows incorporation of nanoemulsions into products that need to be optically clear and enables their easy observation by light microscopy. Third, preparation of nanoemulsions requires much lower concentrations of surfactants compared to macro- and microemulsions $^{28}$ or no surfactant at all, ${ }^{74}$ which substantially improves their biocompatibility. Although nanoemulsions have similar droplet size to microemulsions (10 to $100 \mathrm{~nm}^{71}$ ), they are much more resistant to physical and chemical changes than microemulsions, ${ }^{72}$ which tend to easily destabilize with changing composition or environmental conditions such as temperature and $\mathrm{pH}$. Other advantages of nanoemulsions include low polydispersity of the droplets $(<10-20 \%$ vs. $>40 \%$ for macroemulsions ${ }^{72}$ ) and improved bioavailability of compounds encapsulated in the droplets. ${ }^{75}$ The fundamental difference between nanoemulsions and microemulsions is that nanoemulsions are thermodynamically unstable, i.e. they are not in chemical equilibrium and do not form/reform spontaneously (without energy input) when the emulsifier, oil and aqueous phase are brought together.$^{27}$ However, they are kinetically stable, which means that they remain stable for extended periods of time (ranging from several days ${ }^{76}$ to several years ${ }^{77}$ ), but over time will eventually separate into two phases due to their natural tendency to lower their interfacial area and interfacial energy (which is lower in the two-phase state). The advantage of this metastability is that it removes the compositional limitation of microemulsions required for their thermodynamic stability. As a result, nanoemulsions can be functionalized with much wider variety of compounds. ${ }^{78}$

\section{Factors affecting nanoemulsion droplet size}

Droplet size is a key factor that determines nanoemulsion stability and physicochemical properties including its transparency, 


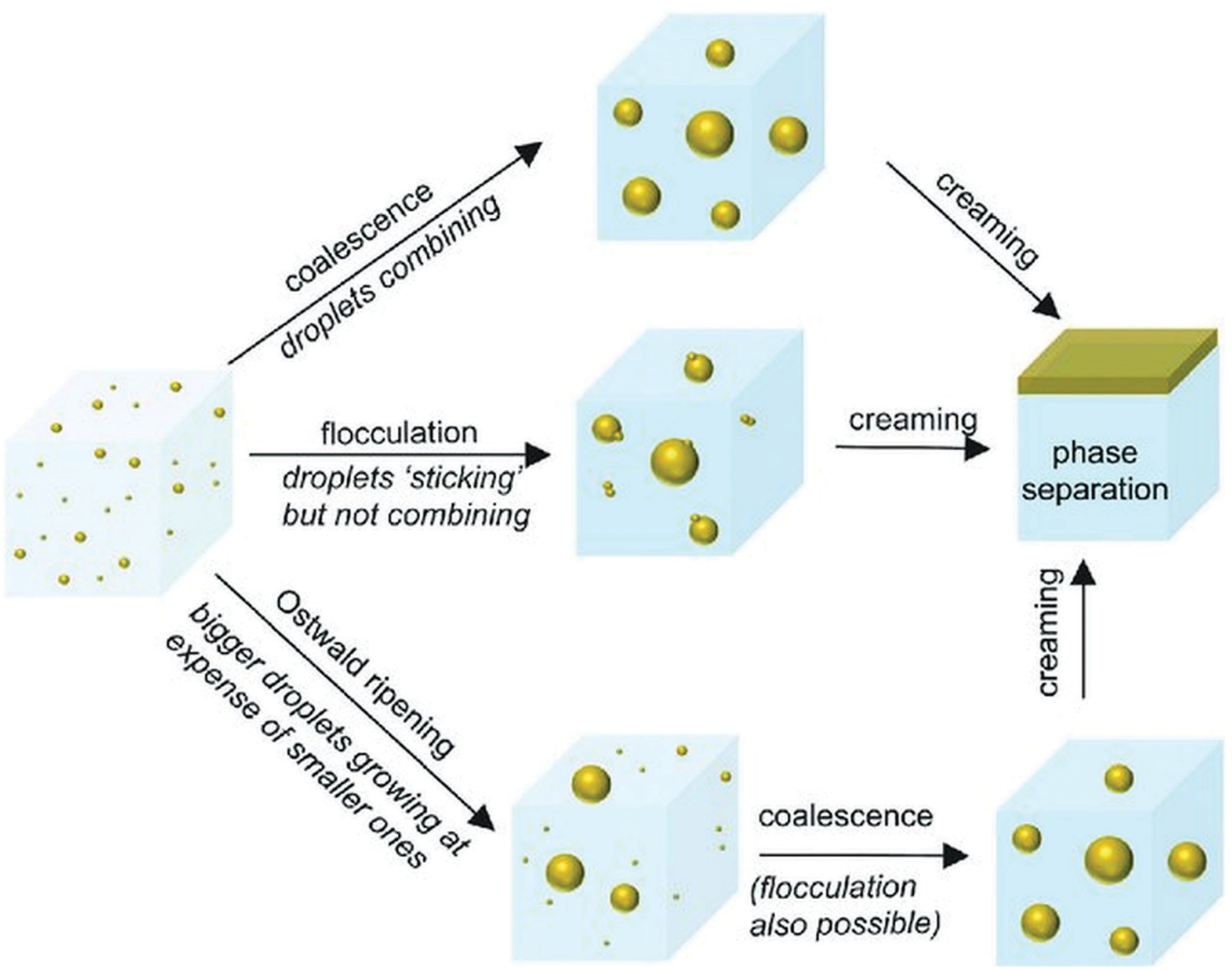

Fig. 2 Nanoemulsion destabilization mechanisms: Ostwald ripening, flocculation and coalescence. Though nanoemulsions can be destabilized through any of the possible routes, initial growth of droplets generally occurs through Ostwald ripening. Coalescence and flocculation become more prevalent as the droplet size increases. Copyright $($ CThe Royal Society of Chemistry 2016. Reproduced from ref. 72: https://doi.org/10.1039/C5SM02958A available via license: CC BY-NC 3.0.

density and rheological properties. ${ }^{79,80}$ Nanoemulsion droplet size depends primarily on applied emulsification method (e.g. high or low energy method, see section "Nanoemulsion preparation methods"), process parameters (e.g. shear force, feed pressure of dispersed phase, emulsification time, temperature, etc. ${ }^{80}$ ), phase mixture composition (e.g. type of emulsifier, oil and aqueous phase, and their relative concentrations), and the physicochemical properties of the immiscible phases (e.g. interfacial tension, solubility and viscosity). ${ }^{80,81}$ The final size of nanoemulsion droplet is the resultant of droplet break-up and coalescence processes. ${ }^{28}$ Break-up of the droplets can be induced by shear stress applied to the dispersed phase. Increasing shear force or emulsification time usually leads to formation of smaller droplets. ${ }^{72,80,82}$ The resistance of the droplets to deformation is determined by the Laplace pressure (the difference in the pressure inside and outside the droplet), which can be reduced by adding a surfactant into the oil/water mixture. ${ }^{28,83}$ In general, an increase in the surfactant concentration lowers the interfacial tension between the dispersed phase and continuous phase ${ }^{84}$ leading to reduction in droplet diameter. ${ }^{80,85,86}$

Droplet size correlates also with surfactant surface activity and molecule size, which both influence the rate of surfactant adsorption to the surface of newly formed droplets. ${ }^{28,83}$ Smallmolecule surfactants (such as sodium dodecyl sulfate, SDS and Tween) adsorb more rapidly to the droplet surface and thus tend to produce smaller droplets than larger surfactants (e.g. caseinate and $\beta$-lactoglobulin) under the same emulsification conditions. ${ }^{80,81,87}$ Nanoemulsion droplet size can be also controlled by altering relative viscosity of the dispersed phase to the continuous phase. As the viscosity of the disperse phase increases, it becomes more difficult to break up, which increases the size of the droplets. ${ }^{88}$ Increasing viscosity of the continuous phase has the opposite effect - it reduces the size of the droplets due to higher shear stress generated during emulsification. ${ }^{80,83,89}$ Another parameter affecting final droplet size is temperature. Temperature strongly influences viscosity 
of the dispersed and continuous phase, as well as solubility of the emulsifier in the oil and water mixture. ${ }^{84}$ Nanoemulsions produced at higher temperatures contain smaller droplets of broader size distribution, which results from enhanced rate of coarsening of the droplets via Ostwald ripening and coalescence. $^{71,84}$

\section{Nanoemulsion stability}

Nanoemulsion stability is defined as its ability to resist changes in the physicochemical properties and droplet size over time. ${ }^{90}$ As mentioned before, nanoemulsions are thermodynamically unstable, but kinetically stable systems in nonequilibrium state. The lower the droplet size, the higher the stability of nanoemulsion. ${ }^{90}$ This effect results from lower attraction between smaller droplets and their reduced coalescence. Initial growth of droplets leading to nanoemulsion separation occurs predominantly via Ostwald ripening. ${ }^{28}$ Ostwald ripening is based on incorporation of smaller droplets into larger droplets (Fig. 2) driven by differences in the pressure between the inside of the droplets and the continuous phase, as well as differences in solubility of non-uniformly sized droplets in the continuous phase. Since smaller droplets display higher solubility in the continuous phase,${ }^{70}$ Brownian motion and random collisions between the droplets of different sizes causes inclusion of smaller droplets into the larger ones. Ostwald ripening phenomena is largely dependent on the solubility of the dispersed phase in the continuous phase. ${ }^{91}$ The ripening process can be minimized by selecting oil and water phases that are highly immiscible, i.e. the dispersed phase solubility in the continuous phase is very low. ${ }^{92}$ As the droplets increase in size, coalescence and flocculation become more prevalent mechanisms of nanoemulsion separation.

The period of time after which nanoemulsion will separate is highly variable and can be controlled by a number of factors including nanoemulsion composition (emulsifier type and concentration, water-to-oil volume ratio, presence of additives such as co-surfactants, etc.), droplet polydispersity index, physicochemical properties of mixture components (e.g. viscosity, density, interfacial tension, polarity, ionic strength) and temperature. ${ }^{72}$ One of the most important factors affecting nanoemulsion stability is choice of the emulsifier. The key properties that need to be considered during emulsifier selection is its size and charge. Nanoemulsions can be stabilized using ionic (cationic or anionic) or non-ionic emulsifiers. Ionic emulsifiers contain a charged polar group (positively charged in cationic emulsifiers or negatively charged in anionic emulsifiers) and work by forming a charged shell around the droplets causing electrostatic repulsion between them. The degree of repulsion between the droplets correlates with the surface charge and ionization degree of emulsifier molecules, which in turn depend on nanoemulsion $\mathrm{pH}$ and presence of other charged species (e.g. electrolytes). ${ }^{70}$ As a result, stabilizing effect of ionic emulsifiers is highly sensitive to nanoemulsion composition. This restricts application possibilities of ionic emulsifiers to only certain types of emulsions. For example, cationic emulsifiers are effective in low $\mathrm{pH}$ and neutral solutions, but not in alkaline solutions, while anionic emulsifiers are more suitable for alkaline emulsions. Non-ionic emulsifiers are considered more effective in stabilization of different kinds of nanoemulsions. ${ }^{70}$ The molecules of non-ionic emulsifiers contain large, bulky, non-charged polar groups that sterically hinder the droplets from coalescing. This stabilization mechanism is not sensitive to medium $\mathrm{pH}$ and composition. Thus, most nanoemulsions are prepared using emulsifiers from this group such as Pluronics, ${ }^{70}$ Tween-80, Span 80 or Brij $30 .^{76}$

Another important parameter taken into account when choosing optimal emulsifier is its hydrophilic-lipophilic balance (HLB). HLB is a measure of emulsifier partitioning tendency between oil and water phase. It is used to predict emulsifier's ability to form a particular type of emulsion. HLB correlates with emulsifier solubility in water and oil, as well as size and strength of its hydrophilic and lipophilic moieties. ${ }^{93}$ It is calculated from the weight percentage of the hydrophilic groups to the hydrophobic groups in a molecule. ${ }^{94}$ The HLB scale ranges from 0 to 20. HLB equal to 10 means that the emulsifier is equally attracted to the water and oil phase (i.e. is equally hydrophilic and hydrophobic). Emulsifiers with HLB above 10 (e.g. phospholipids, proteins, potassium/sodium salts) are more hydrophilic and therefore tend to form oil-in-water emulsions. ${ }^{94}$ Emulsifiers with HLB below 10 (e.g. glycerol esters, sorbitol fatty acid esters, propylene glycol fatty acid esters) are more hydrophobic and promote formation of water-in-oil emulsions. ${ }^{93}$ To achieve maximum nanoemulsion stability, HLB value should be matched to the HLB value of oil used as the non-polar phase. ${ }^{95}$ For instance, vegetable oil emulsions typically require emulsifiers with an HLB in the 7-8 range, while in the case of castor oil emulsions HLB should be around 14. However, the HLB concept has certain limitations such as low accuracy of predicting type of emulsions formed by some emulsifiers. ${ }^{96,97}$ For example, depending on emulsification process variables such as temperature or emulsifier concentration, the same emulsifier can form both w/o and o/w emulsions. ${ }^{95}$ In addition, $\mathrm{o} / \mathrm{w}$ emulsions can be produced using emulsifiers across the entire HLB range and the theoretical HLB calculation does not apply to blends of different emulsifiers.

To allow more accurate characterization of emulsifiers, hydrophilic-lipophilic difference (or hydrophilic-lipophilic deviation, HLD) concept has been introduced. ${ }^{98,99}$ HLD takes into account numerous factors characterizing the emulsion such as surfactant concentration and type, hydrophobicity of the oil phase, salinity, temperature and the characteristic curvature $\left(C_{\mathrm{c}}\right)$ of the emulsifier. The $C_{\mathrm{c}}$ value reflects whether the emulsifier has a tendency to curve around an oil droplet in water (negative $C_{\mathrm{c}}$ ) or a water droplet in oil (positive $C_{\mathrm{c}}$ ). Hydrophilic emulsifiers tend to have negative $C_{\mathrm{c}}$ (e.g. sodium laurel sulphate, SLS has a $C_{\mathrm{c}}=-2.3$ ), while hydrophobic emulsifiers have positive $C_{\mathrm{c}}$ (e.g. dioctyl sodium sulfosuccinate has a $C_{\mathrm{c}}$ of 2.6). HLD equal to 0 corresponds to the optimal emulsifier with equal affinity to both phases. A negative HLD value implies that the emulsifier is preferentially soluble in water and tends to produce $\mathrm{o} / \mathrm{w}$ emulsions,${ }^{100}$ whereas positive HLD value means that the emulsifier is more hydrophobic and tends to generate w/o emulsions. 
Another factor strongly affecting nanoemulsion stability is the emulsifier concentration. In most cases, applying higher emulsifier concentrations produces more stable nanoemulsions. ${ }^{101}$ However, in some systems the opposite effect can occur due to various mechanisms of inter-droplet interactions in different nanoemulsions. ${ }^{101}$ Other variables influencing nanoemulsion destabilization rate is temperature, ionic strength, $\mathrm{pH}$ and viscosity of the continuous phase. ${ }^{72,102}$ Ionic strength and $\mathrm{pH}$ of the continuous phase have a major impact on electrostatic interactions and the repulsive barrier between the droplets $^{102,103}$ and therefore most strongly affect emulsions stabilized with ionic emulsifiers. The higher the ionic strength of the continuous phase, the lower the repulsive barrier between the droplets and the higher probability of their flocculation/ coalescence. Temperature alters viscosity of the phases, interfacial tension, adsorption of the surfactant to the droplets, dispersed phase solubility and diffusivity in the continuous phase ${ }^{104}$ which has indirect effect on nanoemulsion stability. Since both interfacial tension and viscosity decrease with an increase in temperature, elevating the temperature facilitates nanoemulsion formation. However, emulsion stability decreases as the temperature rises due to higher solubility of the dispersed phase in the continuous phase and accelerated Ostwald ripening. ${ }^{72,105,106}$ Sharp changes in temperature are particularly harmful for the stability of nanoemulsions. ${ }^{104}$

Nanoemulsion stability can be improved by increasing viscosity of the continuous phase. More viscous continuous phase slows down gravitational separation (flocculation and sedimentation) and reduces the frequency of droplet collisions and coalescence, which contributes to increased resistance of the emulsion to separation. ${ }^{102,107}$ Nanoemulsion stability may be also increased by lowering dispersed to continuous phase volume ratio ${ }^{104}$ and droplet polydispersity index. Lower stability is generally displayed by polydisperse nanoemulsions containing a range of different droplet sizes. ${ }^{28,90}$ As mentioned before, in polydisperse systems smaller droplets display larger solubility in the continuous phase than the large ones. ${ }^{70}$ As the polydispersity of nanoemulsion increases, the differences in solubility between droplets become higher, which in turn accelerates the Ostwald ripening. Over the recent years, many efforts have been devoted to improving control over nanoemulsion stability by using emulsifiers responsive to specific stimuli such as light (e.g. azobenzene modified emulsifiers), ${ }^{108,109} \mathrm{pH}$ (e.g. poly(methacrylic acid-co-methyl methacrylate-co-7-(4-vinylbenzyloxyl)-4-methylcoumarin emulsifier $\left.{ }^{110}\right)$ or salts (e.g. zwitterionic emulsifiers). Stimuli-responsive emulsifiers allow reversible stabilization/destabilization of nanoemulsions in response to physical or chemical changes, which can prove very useful in on-demand site-specific drug delivery.

\section{Nanoemulsion preparation: high and low energy methods}

Nanoemulsion preparation methods can be categorized into two main types: high energy methods and low energy methods. High energy methods employ high shear forces to disrupt the dispersed phase into the nanodroplets. ${ }^{111}$ In low energy methods, the energy required for nanodroplet formation originates from changes in chemical potential of emulsion components, driven by changes in temperature or composition of the oil-water mixture, which allows production of nanoemulsions under gentle mixing conditions. The devices used in high energy methods to generate shear stress include high pressure homogenizers, microfluidizers and ultrasonicators.

High-pressure valve homogenization (HPVH). The high pressure valve homogenizers (e.g. piston gap homogenizer depicted in Fig. 3) are employed to manufacture nanoemulsions with very small droplet size $(<1 \mathrm{~nm}) .{ }^{112}$ In the HPVH method, the emulsifier-rich aqueous phase is added to an organic phase and mixed with a high-speed mixer (e.g. Ultra Turrax disperser or Silverson mixer) to form a coarse emulsion. The resulting emulsion is introduced into a HPVH device for several homogenization cycles under high pressure (up to $300 \mathrm{MPa}$ ), which allows formation of nanosized droplets. The disruptive force in the homogenization chamber of high pressure homogenizers can be generated by pushing the emulsion under high pressure through a narrow valve (10-100 $\mu \mathrm{m}$ in diameter) such as a small orifice in an orifice plate or a narrow gap between a stator and a rapidly moving rotor (in rotor stator homogenizers). ${ }^{113-115}$ Shear stress may be also produced by colliding two jets of

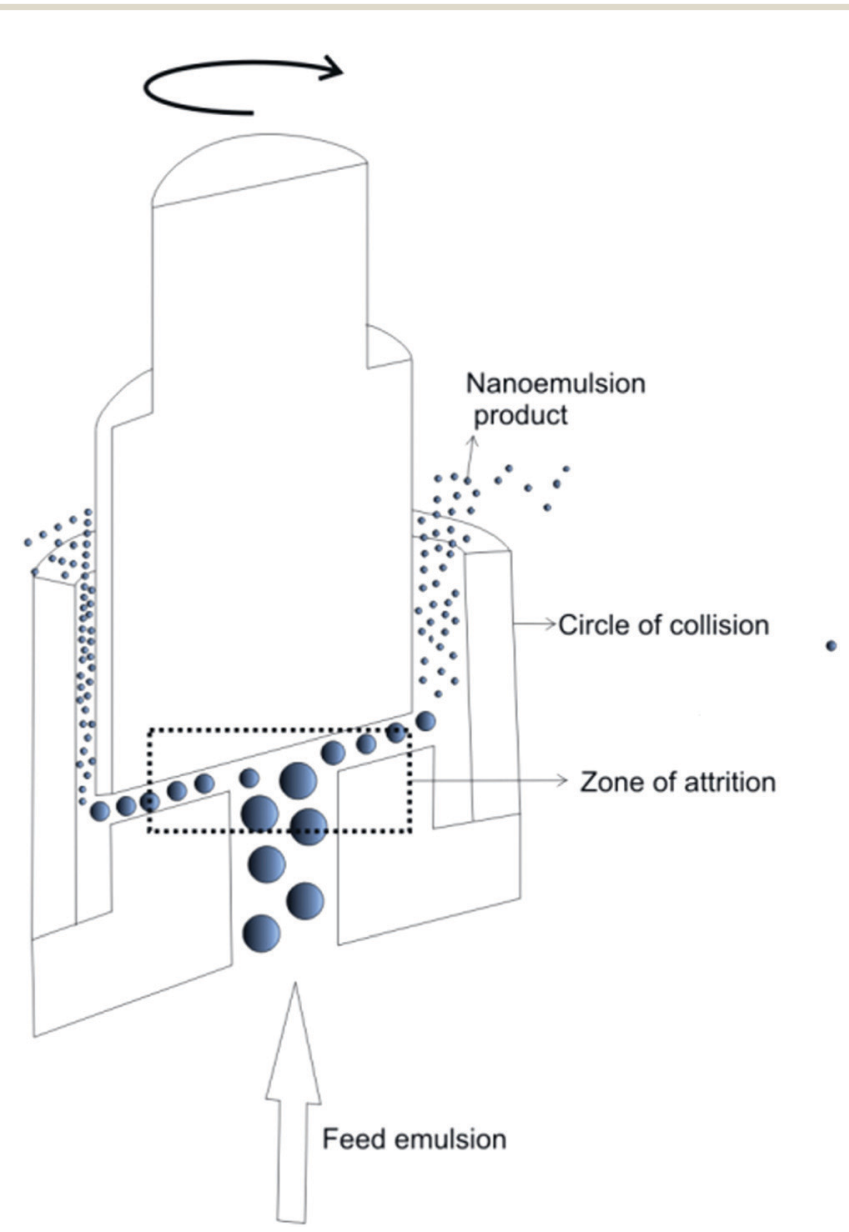

Fig. 3 Schematic illustration of high-pressure homogenization performed in piston gap homogenizer. Copyright (C2017 Elsevier B.V. Reproduced from ref. 113: https://doi.org/10.1016/j.jconrel.2017.03.008 with permission from Elsevier B.V. 


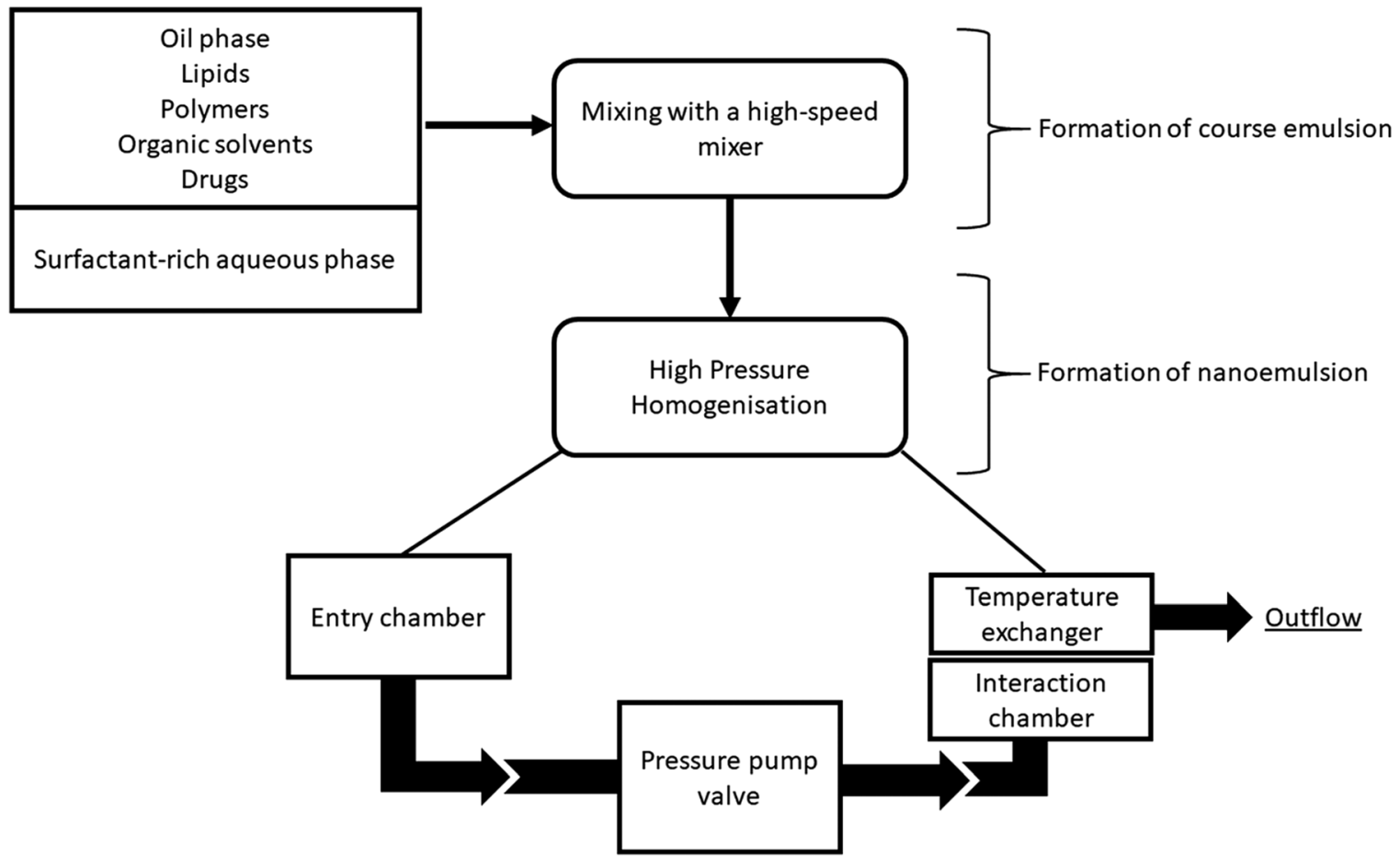

Fig. 4 High pressure homogenization (HPH) technique. The emulsifier-rich aqueous phase is mixed with an organic phase using a high-speed mixer (e.g. Ultra Turrax disperser or Silverson mixer) to form a coarse emulsion. The resulting emulsion is introduced into a HPH device. In the homogenization chamber, hydraulic shear, intense turbulence and cavitation forces disrupt coarse emulsions into nanodroplets. In the interaction chamber, emulsifier molecules adsorb to the newly formed droplets and stabilize them. The disruption and stabilization steps are repeated several times.

the coarse emulsion coming from opposite bores (counter jet dispersers) ${ }^{114,115}$ Hydraulic shear, intense turbulence and cavitation forces disrupt coarse emulsions into nanodroplets. ${ }^{116}$ In the interaction chamber (Fig. 4), emulsifier molecules adsorb to the newly formed droplets and stabilize them. Droplet disruption and stabilization steps are repeated several times until droplets of desired size are obtained. ${ }^{117}$

Microfluidization. Nanoemulsions of precisely controlled droplet size and narrow size distribution can be generated using microfluidic devices. Microfluidic devices are composed of microscale channels of diameters in the 50-300 $\mu \mathrm{m}$ range. During microfluidization, the coarse emulsion is pumped under high pressure (up to $270 \mathrm{MPa}$ ) into an inlet of a microchannel, ${ }^{115}$ which splits into two branches forming a T or Y junction (Fig. 5). The two branches reconnect downstream into one channel called an interaction channel. The shear stress generated in the interaction channel due to collision of two jets of the coarse emulsion, flowing through the microchannels at high velocity, disrupts the coarse emulsion droplets into nanodroplets. ${ }^{118}$ The coarse emulsion is repeatedly passed through the device (up to 100 cycles) until the desired droplet size and dispersity is achieved. ${ }^{113}$ The emulsion feed pressure and flow velocity, number of cycles and droplet recoalescence rate, which depends on type of the emulsifier and viscosity of the phases, determine the final size of the droplets. ${ }^{81}$

Ultrasonication. Ultrasonication is one of the most commonly used methods for production of nanoemulsions. Ultrasonic devices consist of a piezoelectric probe that generates

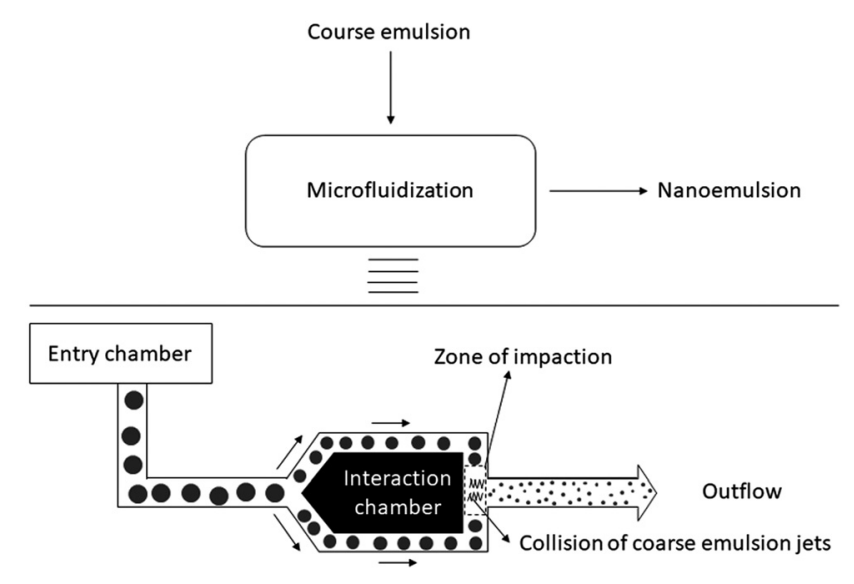

Fig. 5 Schematic illustration of $Y$ junction microfluidic device. Coarse emulsion is pumped under high pressure into a microchannel, which splits into two branches forming an $\mathrm{Y}$ junction. The two branches reconnect downstream into one channel. The shear stress generated in the interaction channel due to collision of two jets of the coarse emulsion disrupts the droplets into nanodroplets.

high energy ultrasonic waves ( $>20 \mathrm{kHz}$ ). When a coarse emulsion is subjected to ultrasonication, the sound waves produce mechanical vibration and acoustic cavitation generating high pressure and turbulence. ${ }^{115,119}$ This leads to formation of cavitation bubbles (Fig. 6) growing in an unstable manner and ultimately imploding. With the collapse of the cavitation bubbles coarse emulsion droplets break up into nanodroplets. ${ }^{120,121}$ 


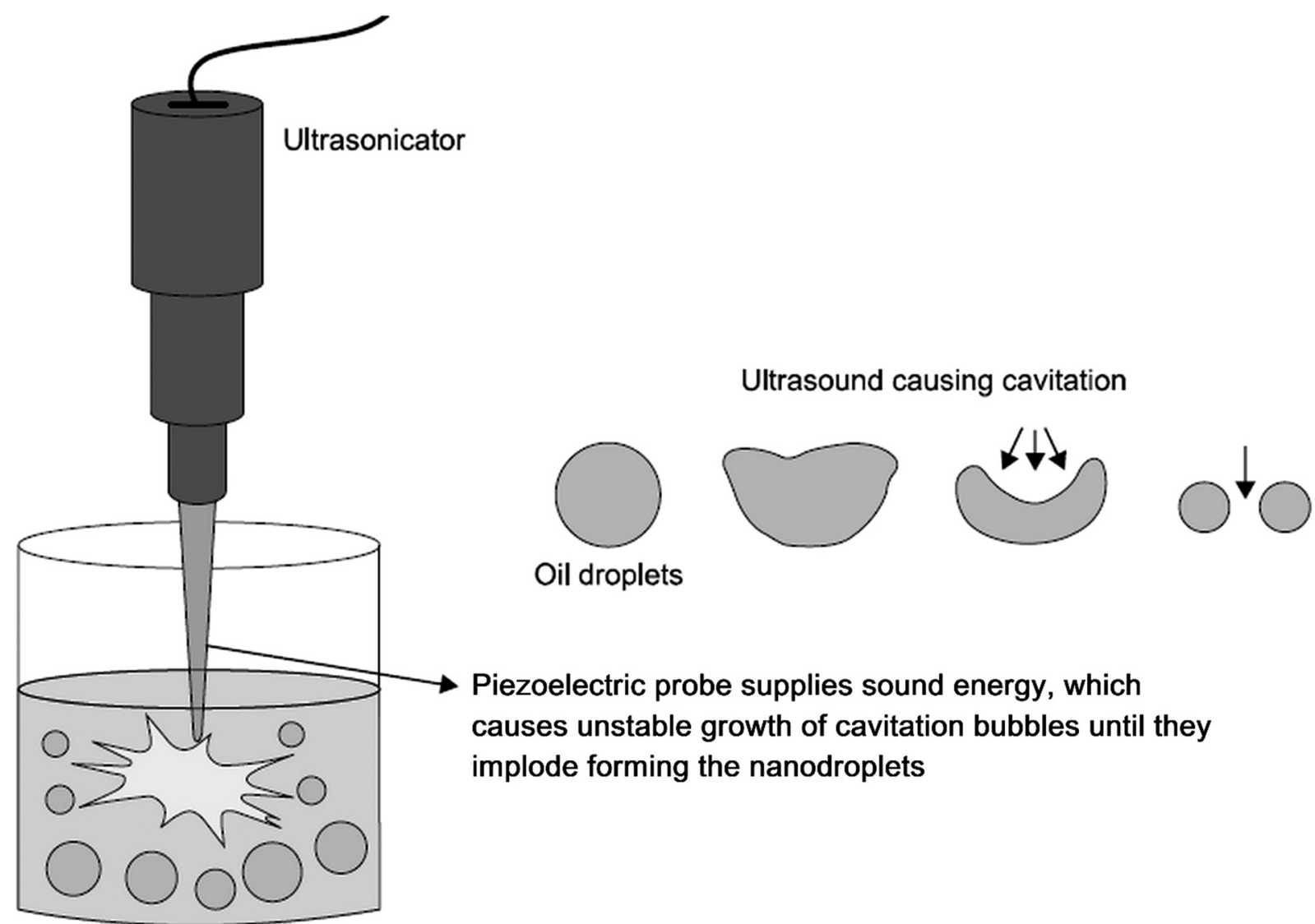

Fig. 6 Preparation of nanoemulsion via ultrasonication. Ultrasonic waves emitted by the piezoelectric probe cause formation of cavitation bubbles, which grow in an unstable manner and ultimately implode. As a result, coarse emulsion droplets break up into nanodroplets. Copyright $\mathbb{C} 2017$ Elsevier B.V. Adapted from ref. 113: https://doi.org/10.1016/j.jconrel.2017.03.008 with permission from Elsevier B.V.

Factors determining final droplet size include the amplitude of ultrasonic waves and ultrasonication time. ${ }^{122}$ An increase in the sonication time leads to increase in energy input, which reduces the size of the droplets. ${ }^{88}$ Compared to other high energy emulsification methods, ultrasonication requires least energy to generate nanoemulsions. ${ }^{113}$ It also allows formation of nanoemulsions without the use of surfactants. ${ }^{88,123}$

One of the biggest advantages of high energy methods lies in their versatility. They allow effective production of nanoemulsions from oil-water mixtures of almost any composition, including mixtures without surfactants. ${ }^{113}$ The major limitation of these systems is high cost of homogenizers and large amount of heat generated by friction of the emulsions on the homogenizer surfaces, which needs to be dissipated by cooling of the device during its operation. ${ }^{113,124}$ The heat generated during homogenization rules out high energy methods from certain applications such as formulation of nanoemulsions containing thermosensitive compounds including proteins and nucleic acids. ${ }^{113}$ Another drawback of high energy nanoemulsification is degradation and fragmentation of high molecular weight compounds (e.g. polymers such as starch, ${ }^{125}$ methylcellulose ${ }^{126}$ chitosan $^{127}$ ) leading to reduction in their molecular weight and changes in their properties such as viscosity or degradation rate.
The limitations of high energy methods such as exposure of formulation to high shear stress can be overcome by low energy nanoemulsification methods. As mentioned before, in these methods, nanoemulsion formation is induced by changes in temperature or composition of the oil-water mixture. The energy input required for nanoemulsification is generated by changes in the chemical potential of the emulsion components, which allows formation of nanoemulsions by gentle mixing of water and oil phase. Low energy methods include selfnanoemulsification method, solvent displacement method, bubble bursting method, transitional phase inversion (TPI) and catastrophic phase inversion (CPI) method. The TPI can be conducted as phase inversion temperature (PIT) or phase inversion composition (PIC), whereas the CPI is performed as emulsion inversion point (EIP).

Phase inversion temperature (PIT) method. In this approach, nanoemulsion formation is driven by a change in temperature of oil/water/surfactant mixture. ${ }^{128}$ Emulsification process relies on temperature-dependent changes in hydrophilicity and lipophilicity of emulsifier molecules. Temperature influences the degree of hydration of the polar heads in the surfactant molecules, which alters the spontaneous curvature of the surfactant layers surrounding emulsion droplets ${ }^{129}$ leading to conversion of o/w to w/o nanoemulsion (or vice versa) via an intermediary 


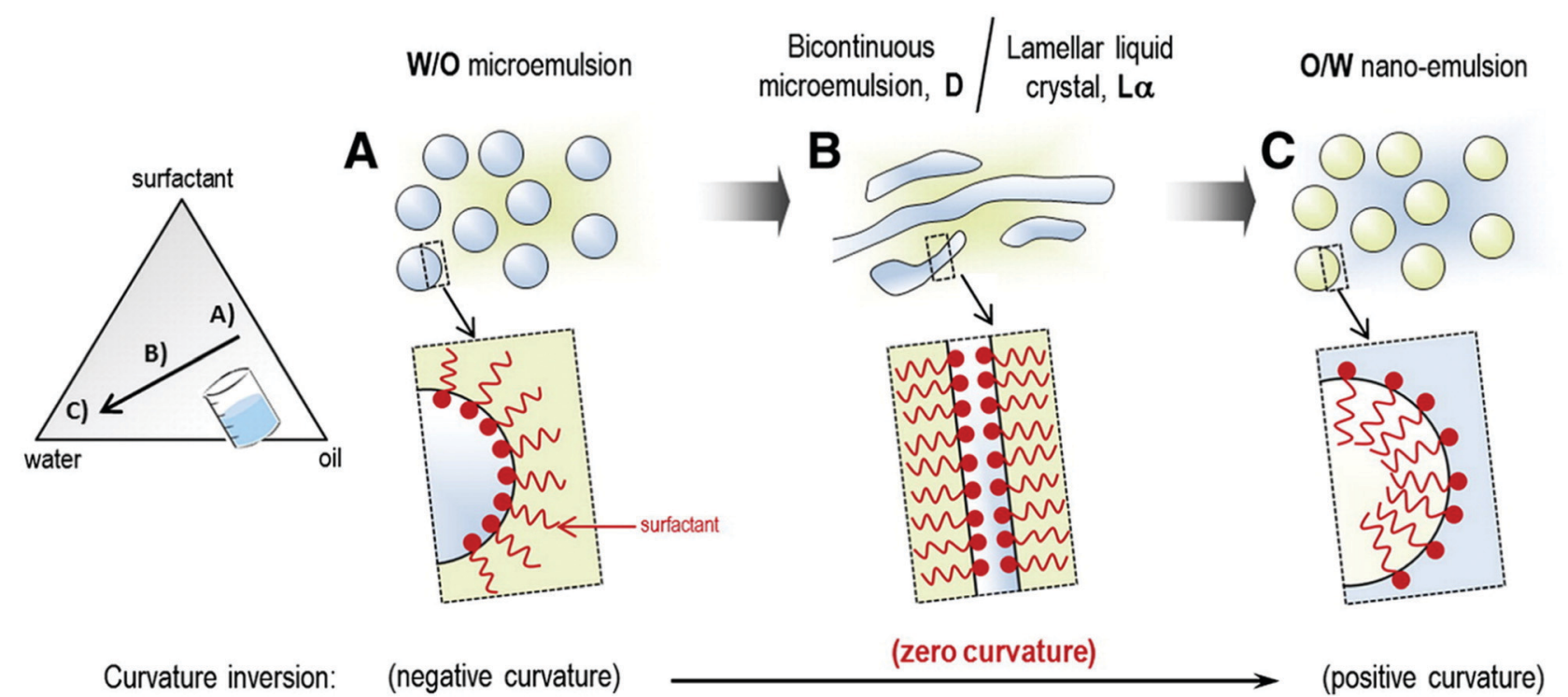

Fig. 7 Schematic representation of nanoemulsion formation by phase inversion composition (PIC) method. Copyright $C 2012$ Elsevier Ltd. Reproduced from ref. 132: https://doi.org/10.1016/j.cocis.2012.07.003 with permission from Elsevier Ltd.

bicontinuous phase or lamellar liquid crystalline phase shown in Fig. 7B. ${ }^{115,117}$ Bicontinuous phase is formed at hydrophilelipophile balance (HLB) or phase inversion temperature (PIT) specific for a particular formulation blend, when the surfactant layer has zero curvature and equal affinity to aqueous and oil phase. ${ }^{106}$ As a result, there is no tendency to form either o/w or w/o emulsion. When the system is cooled past phase inversion temperature, the surfactant layer curvature becomes positive and an w/ o emulsion converts to o/w nanoemulsion. ${ }^{131}$ When the oil, water and surfactant blend is heated past PIT, the surfactant becomes more soluble in oil phase than in the water phase and its curvature becomes negative causing inversion of the system towards w/o nanoemulsion. ${ }^{115,130}$ The efficiency of nanoemulsion formation is influenced by the rate of cooling or heating of the system. ${ }^{132}$

The PIT method offers higher emulsification efficiency and produces nanoemulsions of lower polydispersity index compared to the PIC method (described below). However, the major drawback of this technique is rapid temperature changes, which can be detrimental to the stability and bioactivity of thermosensitive compounds such as proteins. In addition, PIT method can utilize only those types of surfactants that are sensitive to changes in temperature such as polyethoxylated (POE) non-ionic surfactants. In case of POE surfactants, altering the temperature causes a change in the hydration of the poly(oxyethylene) chains, which in turn alters their molecular geometry, affinity to water and oil and the spontaneous curvature. $^{133}$

Phase inversion composition (PIC) method. In phase inversion composition method, nanoemulsification is triggered by changes in oil-water-surfactant mixture composition, while temperature remains constant. Nanoemulsion formation is induced by altering phase volume ratio or by introducing compounds modifying the hydrophilicity/lipophilicity of the surfactant. One of the most straightforward PIC approaches is based on slow addition of one of the components (oil or water) to a mixture of the other two components (water-surfactant or oil-surfactant, respectively). ${ }^{117}$ For example, slow addition of water to a w/o emulsion (Fig. 7A) leads to an increase in hydration of surfactant molecules and surfactant spontaneous curvature. At the hydrophilic-lipophilic balance, spontaneous curvature of the surfactant layer reaches zero and a lamellar or bicontinuous phase is created (Fig. 7B). If more water is added, the surfactant layer curvature becomes positive leading to phase inversion and formation of $\mathrm{o} / \mathrm{w}$ nanoemulsion (Fig. 7C). Phase inversion can also be induced by adding salt or changing $\mathrm{pH}$ of the mixture. ${ }^{134}$ Adding salt to an $\mathrm{o} / \mathrm{w}$ nanoemulsion stabilized with ionic emulsifier leads to a change in the electric charge of the surfactant, which results in conversion of $\mathrm{o} / \mathrm{w}$ into $\mathrm{w} / \mathrm{o}$ emulsion. ${ }^{135}$ Conversely, w/o nanoemulsions containing high salt concentrations can be converted to $\mathrm{o} / \mathrm{w}$ nanoemulsions by their dilution with water. ${ }^{136}$

The mechanism of nanodroplet formation in the PIC method is analogous to the one in the PIT technique. However, since PIC method is performed at constant temperature, it can be applied to much wider range of formulations that the PIT method, including those containing thermally sensitive compounds. PIC technique is also more suitable for large-scale production of nanoemulsions as it is easier to add water or oil to a large volume of emulsion than to produce a sudden change in its temperature. Moreover, the PIC approach is not restricted to POE surfactants. Nonetheless, this type of surfactants is broadly applied for the preparation of nanoemulsions by the PIC method.

Self-nanoemulsification method. In the spontaneous nanoemulsification method, formation of nanoemulsion is achieved without changing the spontaneous curvature of the surfactant. Nanoemulsion formation is initiated by mixing a pure aqueous phase with a mixture of oil, surfactant and a water-miscible 
solvent. ${ }^{129}$ Rapid diffusion of solvent molecules from the oil phase to the aqueous phase causes intense turbulence at the water/oil interface leading to droplet formation. Spontaneous formation of nanoemulsion results from combining two liquids that are thermodynamically stable alone, but create a nonequilibrium state when they are brought together. Resulting nanoemulsion has lower Gibbs free energy compared to the separated state. ${ }^{112}$ Organic phases used in spontaneous nanoemulsification methods typically contain low percentage of oil and high percentage of solvent (high solvent/oil ratio), which increases the rate of solvent diffusion and intensity of turbulence $^{142}$ and results in formation of smaller droplets. The size of the droplets is also influenced by the type and the structure of surfactant, as well as phase volume ratio and viscosity. ${ }^{143}$

An important advantage of spontaneous nanoemulsification is that it can be performed under mild conditions (gentle mixing and room temperature) either in the presence or absence of surfactants. ${ }^{144}$ The spontaneous nanoemulsification mechanism is often utilized in self-nanoemulsifying drug delivery systems (SNEDDS). SNEDDS are anhydrous homogenous liquid mixtures composed of an oil phase, a surfactant, a co-emulsifier and a drug, which spontaneously form an $\mathrm{o} / \mathrm{w}$ nanoemulsion upon dilution with water under gentle stirring. ${ }^{145}$ When SNEDDS are introduced into the aqueous environment of the gastrointestinal tract, they form o/w nanoemulsion with a help of agitation created by stomach digestive motility. ${ }^{146}$ SNEDDS are widely used to increase adsorption and bioavailability of hydrophobic bioactive compounds.

Emulsion inversion point (EIP) method. In the EIP method, the phase inversion occurs through catastrophic phase inversion (CPI) mechanism. In the catastrophic inversion, the surfactant ${ }^{137}$ and all variables affecting its HLB are held constant and the volume ratio of oil and water is altered. ${ }^{138}$ The dispersed phase is titrated into the continuous phase leading to increasing volume fraction of the dispersed phase. When droplet population reaches critical packing, the phase inversion occurs. ${ }^{139}$ For instance, titrating water phase into a stirred surfactant-oil mixture causes the system to invert from w/o emulsion to o/w nanoemulsion $^{140}$ (Fig. 8). The mechanism of catastrophic phase inversion depends on water and oil phase composition and volume ratio, surfactant type, concentration, temperature, agitation rate, vessel geometry and surface wetting. ${ }^{137}$

Solvent displacement method. Solvent displacement method, also known as the nanoprecipitation method, is based on the interfacial deposition of polymeric nanoparticles after the displacement of a semi-polar solvent miscible with water (present in a polymer solution) by a non-solvent. Nanoparticles are formed by a dissolution of the polymer in a water-miscible organic solvent (e.g. acetone, ethanol, ethyl methyl ketone) followed by a drop-wise transfer or injection of the organic phase into an aqueous phase containing a surfactant (Fig. 9). Rapid diffusion of organic solvent into the aqueous phase leads to spontaneous nanoemulsification. ${ }^{147-149}$ Subsequent evaporation of the solvent leads to conversion of nanoemulsion droplets into solid polymer nanoparticles. ${ }^{150}$

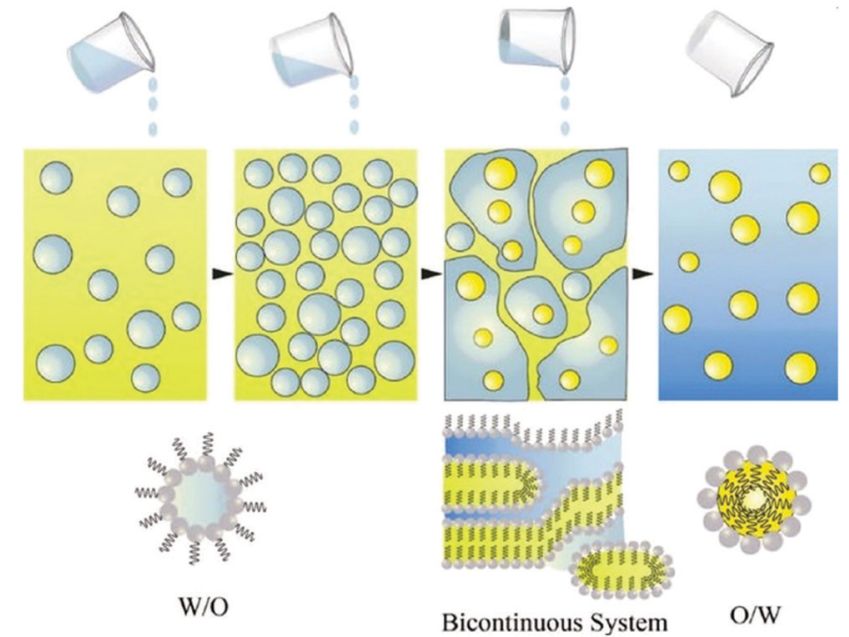

Fig. 8 Schematic representation of low-energy nanoemulsification by the catastrophic phase inversion (CPI) method. The amount of water added to a W/O emulsion is progressively increased until a phase inversion occurs and an O/W emulsion is formed. Copyright $($ Royal Society of Chemistry 2011. Reproduced from ref. 141: https://doi.org/10.1039/ COSM00549E with permission from The Royal Society of Chemistry.

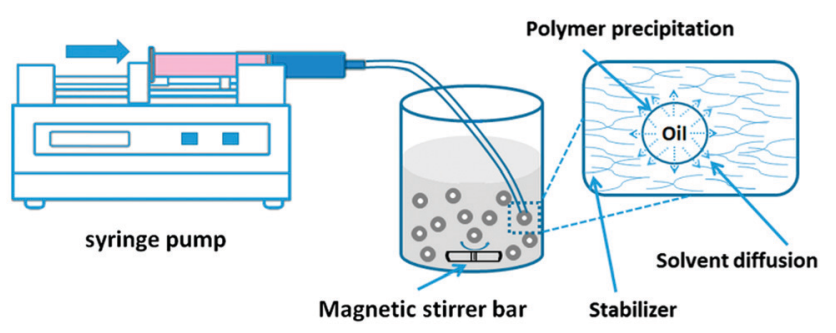

Fig. 9 Solvent displacement method. Nanoparticles are formed by a dissolution of polymer in water-miscible organic solvent (e.g. acetone) followed by a transfer of the organic phase into an aqueous phase containing a surfactant. Rapid diffusion of organic solvent into the aqueous phase leads to spontaneous nanoemulsification. Evaporation of the solvent leads to conversion of nanoemulsion droplets into solid polymer nanoparticles. Copyright ${ }^{\mathbb{R}} 2016$ MDPI. Reproduced from ref. 150: https:// doi.org/10.3390/nano6020026 available under the Creative Commons Attribution License.

Parameters affecting size of the nanoparticles include polymer type and molecular weight, concentration of surfactant, organic phase injection rate, aqueous phase agitation rate and phase volume ratio. ${ }^{151}$ This technique is widely applied for nanoencapsulation of drugs. ${ }^{150}$

Bubble bursting method. This method involves bubbling of a gas through an aqueous phase containing a surfactant towards the oil phase. When the bubble reaches the water-oil interface (Fig. 10), the film of the oil phase is pushed up forming a bubble cap. When the film on top of the air bubble becomes thin enough, it ruptures and generates spatters of oil forming polydisperse droplets in the water phase. ${ }^{152}$ Droplet size can be influenced by oil layer thickness and viscosity, bubble diameter and carbon number of the oil. ${ }^{153}$ The efficiency of nanoemulsion formation is dictated by the frequency of bubbling. 
a

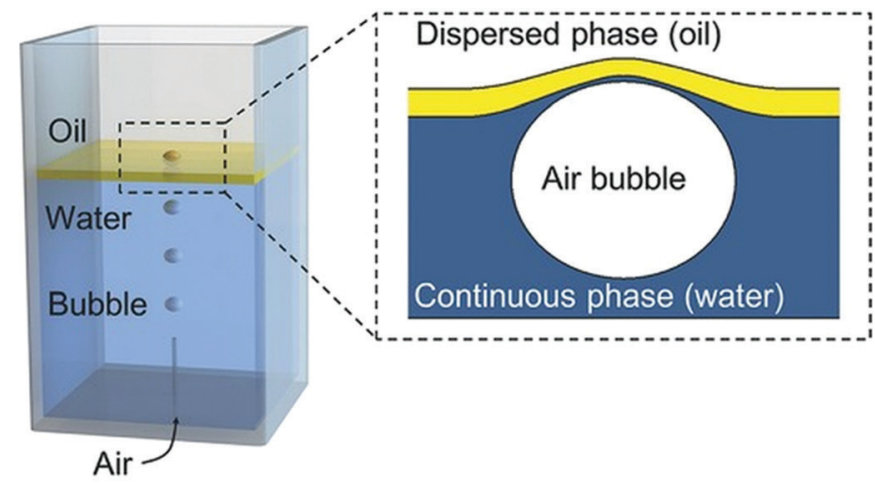

C

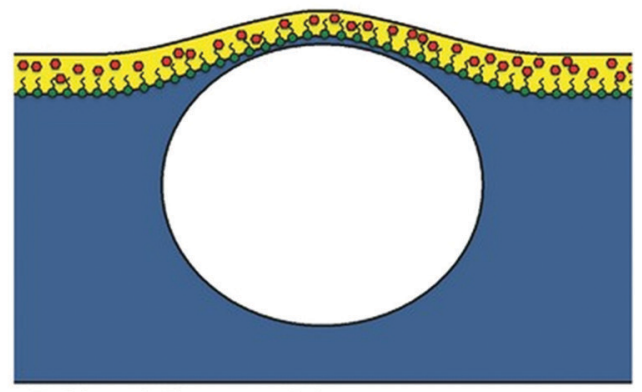

Lipophilic material

S Amphiphilic material

e

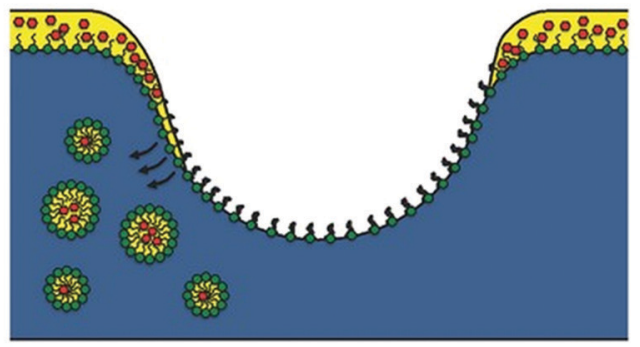

b

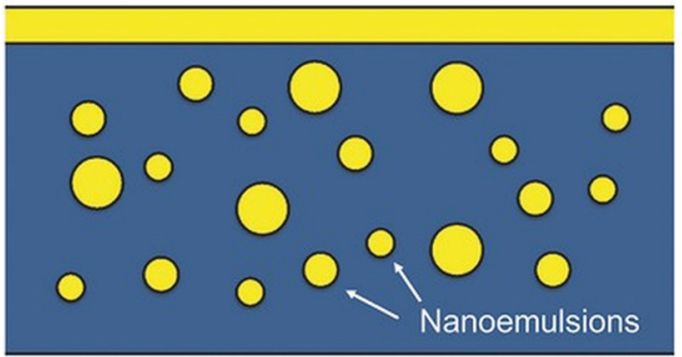

d

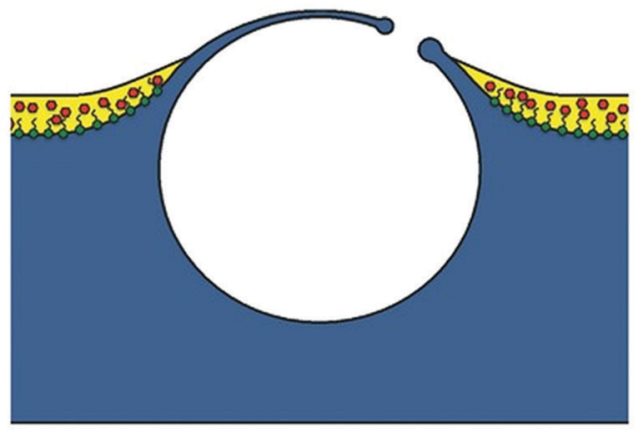

f

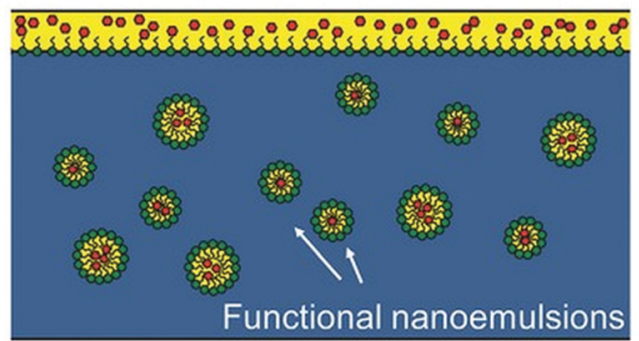

Fig. 10 Schematic illustration of bubble bursting method. (a) Sketch of the experimental set-up. Compound interface $=$ a thin layer of oil on the surface of water column. Inset: Close-up of the deformed compound interface. (b) After bubble bursting, we observe sub-micrometer oil droplets dispersed in the water phase. (c-f) Encapsulation of functional materials with the bubbling platform. (c) Functional materials such as amphiphilic or lipophilic compounds are dispersed in the oil layer. When a bubble reaches the interface, the oil layer is pushed up forming a bubble cap. (d) When oil layer becomes thin enough, it ruptures and generates polydisperse oil droplets that are entrained from the cavity wall into the water phase. (f) $\mathrm{O} / \mathrm{W}$ nanoemulsion droplets loaded with functional compounds. Copyright $\mathbb{C} 2016$ Wiley-VCH Verlag GmbH \& Co. KGaA, Weinheim. Reproduced from ref. 153: https://doi.org/10.1002/adma.201505994 with permission from Wiley-VCH Verlag GmbH \& Co. KGaA.

The main disadvantage of low energy methods is their lack of universality. In all these approaches, formation of nanoemulsions depends fundamentally on composition of oil, water and surfactant blend. Therefore, application possibilities of these methods are strongly limited by the type of immiscible phases and emulsifier that can be used. ${ }^{113}$

\section{Applications of nanoemulsion technology in bone regeneration}

\section{Synthesis of hydroxyapatite nanoparticles via nanoemulsion technology}

Over the past three decades, much attention has been paid to applications of nanoemulsion technology in fabrication of nano-hydroxyapatite $\left(\mathrm{Ca}_{10}\left(\mathrm{PO}_{4}\right)_{6}(\mathrm{OH})_{2}\right.$, HAp) used as inorganic component of orthopaedic and dental implants. ${ }^{4-44,154}$ Accumulating evidence shows that hydroxyapatite synthesis performed in nanoemulsion droplets, which serve as miniaturized reactors (Fig. 11), significantly improves quality of the resulting powders in terms of homogeneity, ${ }^{155}$ dispersity ${ }^{156}$ and osteoinductivity. ${ }^{61,62}$ Crystallization of HAp performed in a very limited, confined volume of nanoemulsion droplets prevents excessive growth of crystals, ${ }^{157-159}$ which allows reducing their size to the nanolevel and yields more monodisperse product. ${ }^{160}$ In addition, separation of nanoreactors by the continuous oil phase prevents agglomeration and flocculation of HAp crystals, ${ }^{161}$ which is one of the main challenges of conventional wet HAp synthesis methods performed in the bulk liquid phase such as hydrothermal method, ${ }^{162}$ double decomposition/precipitation method, ${ }^{163-165}$ semi-hydrothermal method, ${ }^{166,167}$ or hydrolysis method. ${ }^{168,169}$ Hydroxyapatite powders obtained by these 


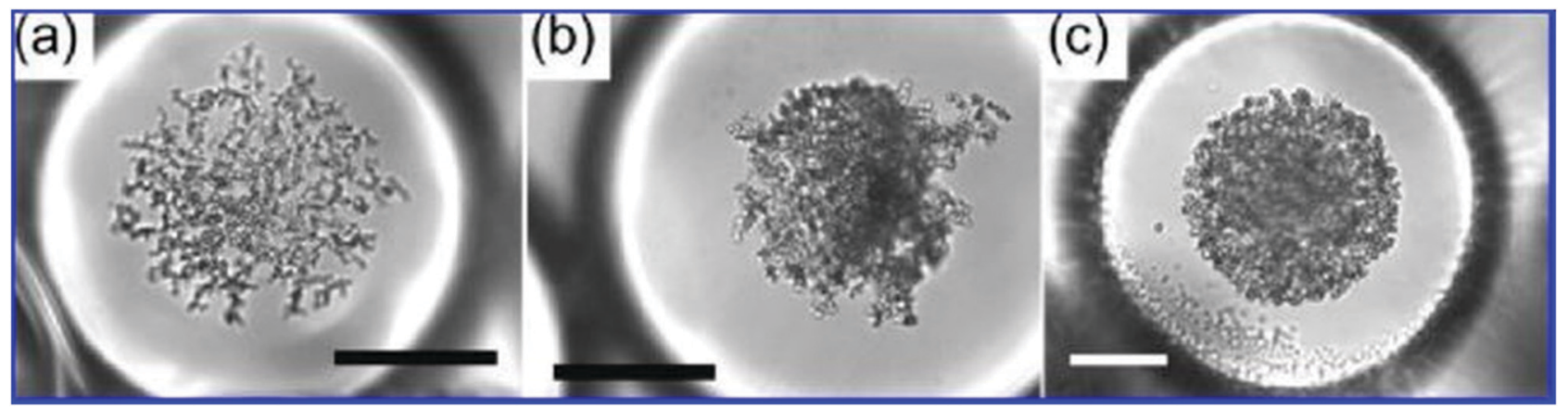

Fig. 11 Optical microscope image of hydroxyapatite nanoparticles synthesized in double emulsion (w/o/w) droplets. Panels (a), (b) and (c) show nanoparticles obtained from precursor solutions containing different concentrations of calcium nitrate and phosphoric acid: (a) $0.1 \mathrm{M}$ and $0.06 \mathrm{M}$, (b) $0.5 \mathrm{M}$ and $0.3 \mathrm{M}$, and (c) $1.0 \mathrm{M}$ and $0.6 \mathrm{M}$, respectively. The structure of the aggregates becomes more compact as the precursor concentration increases. Scale bars are $50 \mu \mathrm{m}$ for (a) and (b) and $30 \mu \mathrm{m}$ for (c). Copyright $(\mathrm{C} 2009$ American Chemical Society. Adapted from ref. 174: https://doi.org/ $10.1021 / \mathrm{cm} 9028935$ with permission from American Chemical Society.

methods are often polydisperse, suffer from inhomogeneous phase composition ${ }^{58,170}$ and poor osteoinductivity related to large crystal size (in the micrometer range) ${ }^{58,59}$ Since hydroxyapatite nanoparticles fabricated via nanoemulsion technology display reduced polydispersity and agglomeration, they exhibit improved densification behavior during sintering, lower incidence of microstructural flaws and higher mechanical resistance of the resulting ceramics. ${ }^{62,171,172}$ Due to the nanoscale size, they also demonstrate higher resemblance to hydroxyapatite nanocrystals occurring in the natural bone $e^{58,59}$ and can stimulate osteogenesis ${ }^{48}$ more effectively compared to their microscale counterparts. ${ }^{61,62}$ For that reason, hydroxyapatite nanocrystals are currently the most desirable form of hydroxyapatite for bone regeneration applications.

Similarly to conventional hydroxyapatite synthesis (performed in bulk liquid reaction media), nanoemulsification-based synthesis is based on chemical reactions between calcium and phosphate sources under alkaline $\mathrm{pH}^{173}$ In the nanoemulsionbased methods, however, the aqueous reaction medium (aqueous solution or organic solvent) is dispersed in the oil phase in the form of nanodroplets (w/o nanoemulsion). HAp synthesis in nanoemulsions is typically a two-step process. In the first step, separate reverse (w/o) nanoemulsions of reactants required for the synthesis, i.e. $\mathrm{Ca}^{2+}$ source $\left(\right.$ e.g. $\mathrm{CaCl}_{2},{ }^{160}$ $\mathrm{CaNO}_{3}{ }^{175}$ ) and $\mathrm{PO}_{4}{ }^{3-}$ source (e.g. $\left.\mathrm{H}_{3} \mathrm{PO}_{4}{ }^{175}\left(\mathrm{NH}_{4}\right)_{2} \mathrm{HPO}_{4}\right)$, are prepared. For this purpose, aqueous solution of $\mathrm{Ca}^{2+}$ or $\mathrm{PO}_{4}{ }^{3-}$ source is mixed with the oil phase composed of a non-polar solvent (e.g. cyclohexane, ${ }^{160} n$-decane $\left.{ }^{175}\right)$, a surfactant (e.g. $\left.\mathrm{CTAB},{ }^{160} \mathrm{AOT}^{175}\right)$ and a co-surfactant (e.g. $n$-pentanol $\left.{ }^{160}\right)$. A co-surfactant is applied to increase flexibility of phase interface, which improves stability of the droplets. ${ }^{176}$ In the second step, nanoemulsions of $\mathrm{Ca}^{2+}$ and $\mathrm{PO}_{4}{ }^{3-}$ source are mixed together at an appropriate ratio (e.g. stoichiometric HAp Ca/P molar ratio 1.67) to initiate HAp synthesis reaction. Mixing of nanoemulsions leads to random collisions and coalescence of the droplets and formation of nanoreactors containing both $\mathrm{Ca}^{2+}$ and $\mathrm{PO}_{4}{ }^{3-}$ ions. The synthesis is induced by adding an alkali (e.g. $\left.\mathrm{NH}_{4} \mathrm{OH}, \mathrm{NaOH}\right)$ to the non-polar phase. Synthesis reactions can be performed at ambient ${ }^{177,178}$ or elevated temperature. ${ }^{160,179}$ Heating of nanoemulsion droplets containing HAp crystals during their growth (for example in an autoclave $e^{160}$ or a microwave $\mathrm{e}^{179}$ ) provides additional process parameters allowing higher degree of control over crystal morphology.

Size and structure of HAp nanoparticles synthesized in nanoemulsion droplets is governed by $\mathrm{Ca} / \mathrm{P}$ precursor molar ratio, reaction $\mathrm{pH}$, temperature ${ }^{181}$ and nanoemulsion droplet size, which in turn depends on applied nanoemulsification method, composition and physicochemical properties of the water and oil phases. ${ }^{175}$ Altering these parameters allows to obtain HAp nanocrystals displaying a broad spectrum of sizes and shapes (e.g. rod-like, sphere-like, needle-like, nanofibers) as depicted in Fig. 12.

Challenges and solutions in synthesis of nano-hydroxyapatite via nanoemulsion technology. Synthesis of hydroxyapatite using nanoemulsions reduces the time required for the reaction due to small volume of the reaction media. ${ }^{160}$ However, reduced medium volume contributes also to one of the key downsides of this method, which is low product yield. For that reason, this approach has been used solely on a laboratory scale. In order to implement it on an industrial scale, it is necessary to scale up the manufacturing process. One of the factors limiting its efficiency is mixing of reactant solutions, which in the methods proposed so far was performed either by vigorous stirring ${ }^{160,175,177-179}$ or ultrasonication. ${ }^{182}$ In order to scale up these methods, it could be beneficial to perform the nanoemulsification step in high throughput turbulence-based mixing devices allowing continuous feeding of the reactant solutions such as turbine homogenizers ${ }^{183-185}$ or impinging jets reactors. ${ }^{186}$ This type of devices has been successfully used in scaling up nanoemulsion-based manufacturing of polymer nanoparticles for drug delivery. ${ }^{184,186}$

Another disadvantage of nanoemulsion-based synthesis of hydroxyapatite is the use of surfactants, which may contaminate the obtained product and adversely affect its biocompatibility. ${ }^{29,30}$ To overcome this issue, a surfactant-free nanoemulsification methods have been devised. Formation of nanoemulsions in the absence of surfactants can be performed via direct pouring technique based on the Ouzo effect. The Ouzo effect relies 


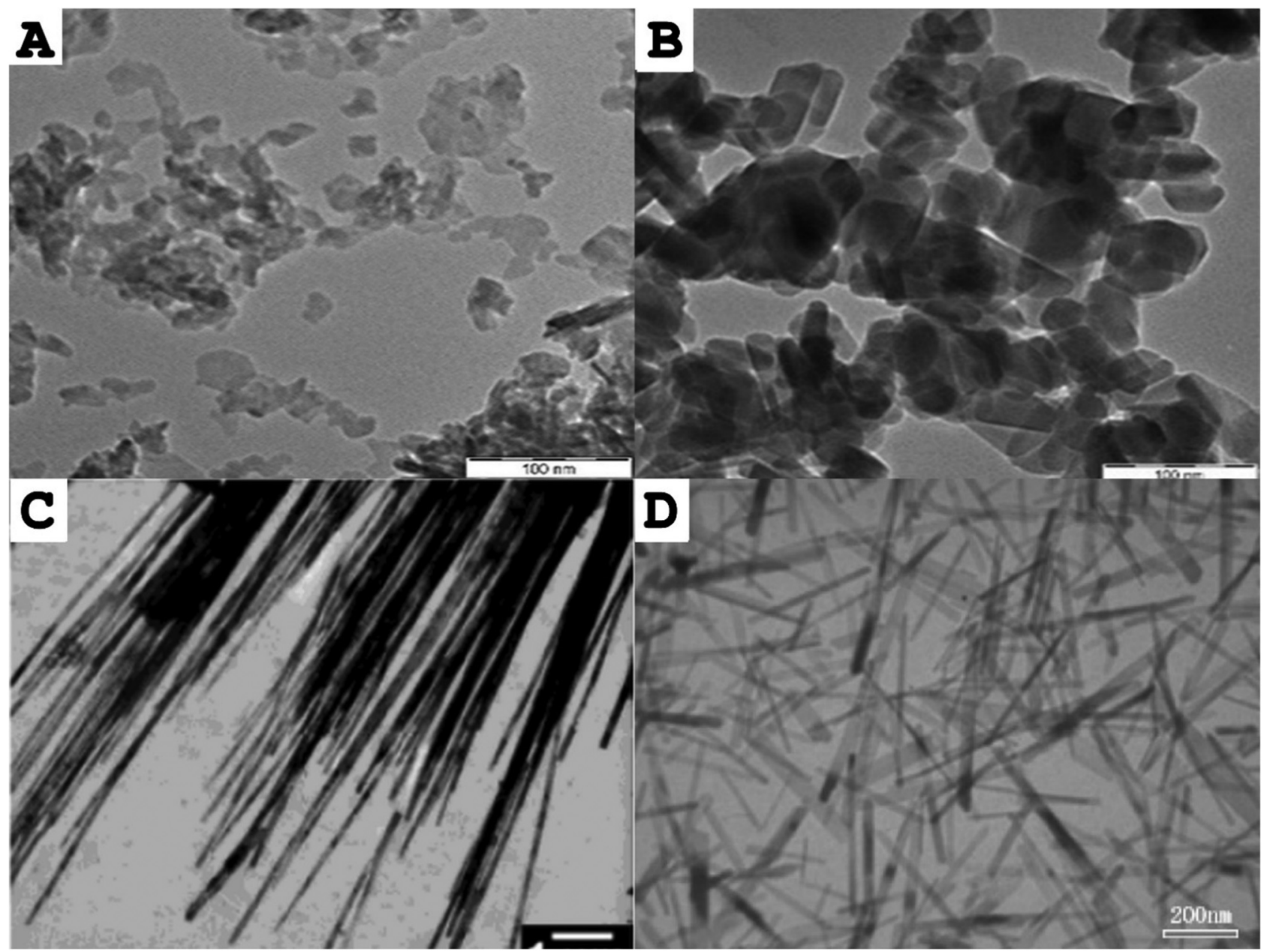

Fig. 12 Transmission electron microscope (TEM) images of different morphologies of hydroxyapatite nanocrystals synthesized in nanoemulsion droplets: (A) Sphere-like nanocrystals; (B) rod-like nanocrystals; (C) nanofibers, (D) needle-like crystals. Scale bars are $100 \mathrm{~nm}$ for (A) and (B), $1 \mu \mathrm{m}$ for (C) and $200 \mathrm{~nm}$ for (D). Parts A and B of the figure were adapted from ref. 177: https://doi.org/10.1016/j.ceramint.2018.04.128 with permission from Elsevier Ltd and Techna Group S.r.l. Part (C) was adapted from ref. 160 https://doi.org/10.1021/la0498197 with permission from American Chemical Society. Part (D) was adapted from ref. 180: https://doi.org/10.1016/j.jpcs.2006.11.026 with permission from Elsevier Ltd.

on a liquid-liquid nucleation process, which occurs when a water-miscible non-polar phase (e.g. organic solvent such as acetone $\mathrm{e}^{155,156}$ ) is poured into a surfactant-free aqueous phase. ${ }^{177,178}$ When the phases are mixed together, the watermiscible solvent becomes supersaturated, resulting in nucleation of solvent droplets and spontaneous formation of a metastable solvent-in-water nanoemulsion. ${ }^{187}$ Synthesis of HAp nanopowders based on the Ouzo effect is performed by adding the phosphorus source and alkali to the aqueous phase and calcium precursor to the non-polar phase prior to mixing of the phases as depicted in Fig. 13. This approach has the added benefit of easy functionalization of hydroxyapatite nanocrystals, typically performed by adding the functional compounds to the organic phase. The functional compound is subsequently incorporated into the structure of HAp during crystal formation. This approach has been successfully applied to obtain synthetic hydroxyapatite nanoparticles functionalized with $\mathrm{CO}_{3}{ }^{2-}$ groups (characteristic for natural carbonated hydroxyapatite), ${ }^{181}$ antibacterial agents $\left(e . g\right.$. $\mathrm{Ag}^{+}$ions $\left.{ }^{156}\right)$ or factors stimulating bone formation (e.g. $\mathrm{Sr}^{2+}$ and $\mathrm{Mg}^{2+}$ ions ${ }^{155,178}$ ) and angiogenesis (e.g. $\mathrm{Co}^{2+}$ ions $\left.^{178}\right)$.

Methods for the synthesis of hydroxyapatite in nanoemulsions developed to date suffer also from relatively poor control over droplet size and size distribution, which may have a detrimental effect on homogeneity and batch-to-batch reproducibility of resulting nanopowders. In current approaches, the degree of control over droplet size is limited by applied nanoemulsification technique (typically vigorous mechanical agitation $^{160,175,177-179}$ or ultrasonication ${ }^{182}$ ). More precise control over droplet size could be achieved by generating nanoemulsion droplets for HAp synthesis in nano- or microfluidic devices, which produce droplets of precisely defined size and very narrow size distribution. ${ }^{188}$ Using this type of devices could provide not only much better control over morphology and dispersity of obtained nanocrystals, but would also allow tracking and observation of individual droplets during HAp crystal growth (Fig. 14). Due to a constant flow rate of fluids in a microfluidic device, it is possible to 


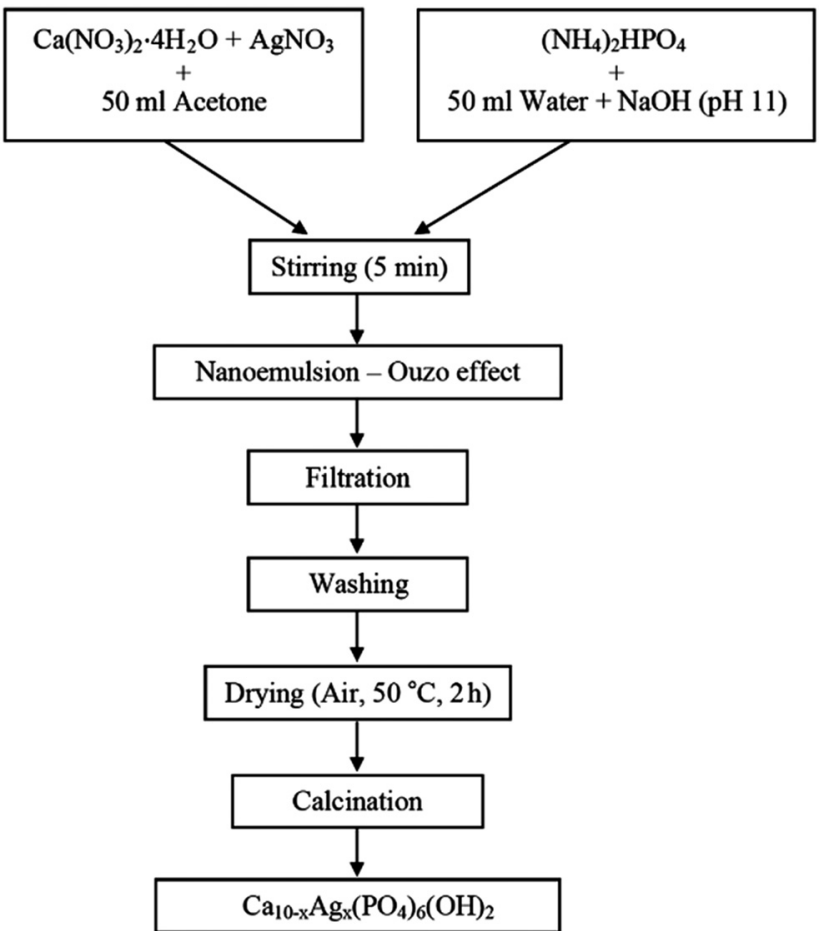

Fig. 13 Flowchart for the synthesis of $\mathrm{Ag}^{+}$-doped nano-hydroxyapatite via direct pouring technique based on the Ouzo effect. Mixing of watermiscible organic solvent (acetone) containing calcium precursor with an alkaline aqueous phase containing phosphorus source leads to spontaneous formation of o/w nanoemulsion. Copyright (C)2016 Faculty of Technology, University of Novi Sad. Adapted from ref. 156: https://www.tf.uns. ac.rs/publikacije/PAC/pdf/PAC\%2033\%2006.pdf licensed under Creative Commons Attribution-Non Commercial-No Derivatives 4.0 International license.

track droplets at different stages of HAp synthesis based on the distance of the droplet from fluid injection port. ${ }^{174}$ Real-time observation of the processes occurring in the droplets could aid in tailoring synthesis conditions based on current crystal morphology and contribute to better understanding of HAp crystal formation mechanism, which is not fully understood. So far, microfluidic devices have been employed only for the synthesis of HAp in microemulsion droplets (Fig. 14). ${ }^{174}$ Combining microfluidic platforms with nanoemulsion-based synthesis of hydroxyapatite could open new perspectives for fabrication of more monodisperse nano-hydroxyapatite crystals of highly controllable size and shape.

In the methods discussed above, HAp synthesis was performed in a liquid environment of water nanodroplets. Alternatively, hydrogel nanospheres can be used as nanoreactors for the crystal growth. Such approach has been employed by Ethirajan et al. ${ }^{182}$ who conducted HAp synthesis in gelatin nanospheres fabricated via reverse nanoemulsion method. To initiate the synthesis, the cross-linked gelatin nanospheres were placed in an aqueous solution of $\mathrm{Ca}^{2+}$ source, where $\mathrm{Ca}^{2+}$ ions were bound to the carboxyl groups of gelatin molecules. Subsequent addition of phosphate ions to the suspension of gelatin nanospheres led to formation of monodisperse HAp nanoparticles inside gelatin nanospheres. This technique
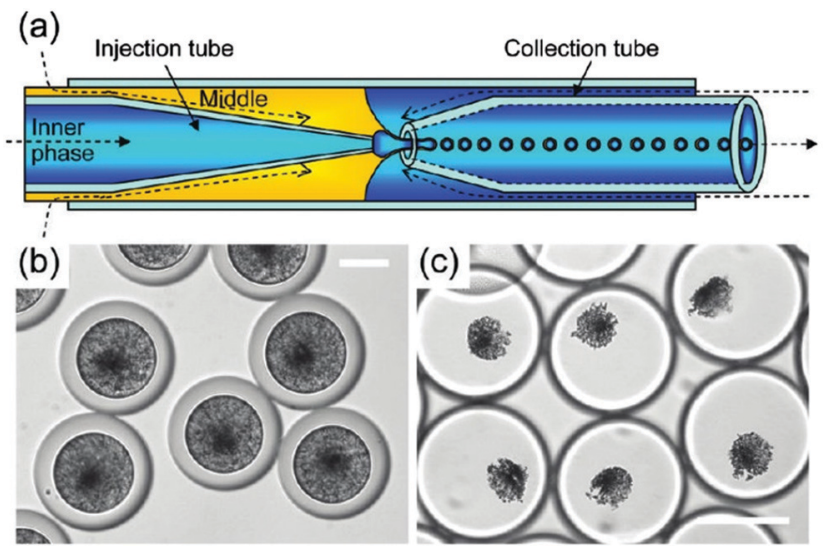

(d)

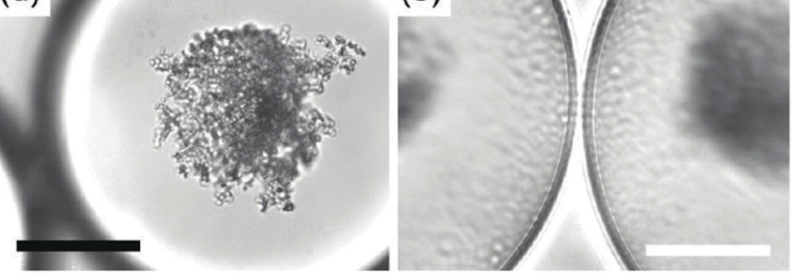

Fig. 14 Synthesis of hydroxyapatite nanoparticles in double W/O/W microemulsion droplets produced using a microfluidic device. (a) Scheme of a microfluidic device. W/O/W double microemulsion droplets are generated by co-extrusion of an aqueous phase (aqueous solution of calcium and phosphorus precursors) and oil phase (silicon oil + surfactant) through a microcapillary into a continuous aqueous phase. The oil phase forms shells around inner aqueous phase droplets $(b-e)$. Optical microscope images of double microemulsion droplets (b and c). Initially, HAp occupies the entire volume of microemulsion droplets (b). As water diffuses into the droplets (due to differences in osmolality), the droplets swell (c). Gradual thinning of oil shells leads to destabilization of the droplets and release of hydroxyapatite crystals. Hydroxyapatite nanoparticle aggregate (d) and oil shells at higher magnification (e). Scale bars are $50 \mu \mathrm{m}$ for (b), (d), (e) and $150 \mu \mathrm{m}$ for (c). Copyright $(\mathrm{C} 2009$ American Chemical Society. Adapted from ref. 174: https://doi.org/10.1021/ cm9028935 with permission from American Chemical Society.

offers an attractive alternative to methods employing liquid nanoemulsions due to several reasons. First, it enables synthesis of HAp nanocrystals and their nanoencapsulation in one step. Second, since it can be performed under physiological conditions, it may be readily applied to co-encapsulate cells (e.g. osteogenic stem cells) with HAp crystals. Such combination could allow formation of bioartificial nanoscaffolds, in which HAp crystals are embedded in a hydrogel matrix (mimicking extracellular matrix) colonized with osteogenic cells. Also, since gelatin nanospheres can be easily assembled (e.g. via 3D-printing ${ }^{189}$ ) or cross-linked together ${ }^{190}$ at physiological temperature, they could be used as building blocks of modular bone tissue constructs. ${ }^{191}$ Due to their small size, HAp-loaded nanospheres could also be implanted or injected directly to the bone defect. Methods allowing synthesis of HAp directly within hydrogel nanocarriers, such as the one discussed above, used in conjunction with cell encapsulation and in vitro tissue culture hold great promise for manufacturing of nanoscaffolds and multifunctional biomimetic bone tissue constructs. 
Current applications of nano-hydroxyapatite fabricated via nanoemulsion technology in bone regeneration. Hydroxyapatite nanoparticles obtained via nanoemulsion technology are intensively explored as inorganic components of composite bone implant materials. Such composites consist of HAp nanocrystals embedded in a soft and elastic biodegradable polymer mimicking organic part of bone extracellular matrix $(\mathrm{ECM})^{58,59}$ such as collagen, ${ }^{192}$ chitosan, ${ }^{193}$ poly(L-lactic acid), PLA, ${ }^{194,195}$ poly(glycolic acid), PGA, ${ }^{196,197}$ poly(D,L-lactic-coglycolic acid), PLGA, ${ }^{196}$ etc. Combination of hydroxyapatite with elastic polymers facilitates shaping of the composites, reduces their brittleness ${ }^{54,55}$ and improves their ability to bear the mechanical loads needed for bone remodeling. ${ }^{198}$ Presence of nano-hydroxyapatite in the composites has been shown to significantly enhance adhesion, proliferation, viability and osteogenic differentiation of cells seeded onto the implant such as human mesenchymal stem cells (hMSCs), ${ }^{199}$ which is attributed to osteoinductive properties of HAp nanocrystals and rougher surface of the material facilitating cell attachment. These qualities of nano-hydroxyapatite have been also used to develop osteoinductive coating materials for bone implants designed to accelerate their osseointegration with the host tissue. An example of such material is a polyelectrolyte multilayer coating composed of alternate layers of polyanionic hyaluronic acid and polycationic collagen reinforced with silicon-carbonated HAp nanoparticles (SiCHAp) mimicking bone mineral composition (2-8 wt\% carbonate, $<1 \mathrm{wt} \% \mathrm{Si}) .{ }^{199}$ Coating synthetic polymer (PLA) films with this kind of material has been demonstrated to effectively improve cell-implant interactions and survival of cells on material surface in vitro. ${ }^{199}$
HAp nanoparticles synthesized in nanoemulsion droplets have been also used for fabrication of 3D scaffolds for cell culture. ${ }^{51,200,201}$ Zhou et al. ${ }^{200,201}$ have designed an interesting composite consisting of PLA microspheres filled with carbonated hydroxyapatite (CHAp) nanospheres. CHAp nanospheres were synthesized via o/w nanoemulsion method and used as the osteoconductive filler of PLA microspheres. CHAp-filled microspheres were then applied as the building blocks of bone tissue scaffolds. $^{201,202}$ The blocks were assembled into a solid porous construct (shown in Fig. 15) by sintering using laser as a power source. The resulting construct exhibited a porous structure containing a network of interconnected macro- and micropores allowing effective transfer of nutrients/oxygen into the scaffold and providing favourable environment for the growth of cells.

Nano-hydroxyapatite obtained via nanoemulsification has also been applied to improve hydrophilicity and bioactivity of hydrophobic bioinert synthetic polymers such as polycaprolactone (PCL). ${ }^{51}$ It has been found that incorporating HAp nanoparticles into such materials (e.g. electrospun PCL nonwovens ${ }^{51}$ ) not only significantly enhances their wettability, but also introduces ionic groups required for scaffold-cell interactions that are absent in non-modified polymer. Because of that, implants containing nano-hydroxyapatite are more readily colonized by cells (either host cells or cells seeded onto them in vitro such as stem cells). ${ }^{199}$

\section{Fabrication of polymer nanoparticles for drug/biomolecule delivery}

One of the most common applications of nanoemulsion technology in bone regeneration is fabrication of polymer
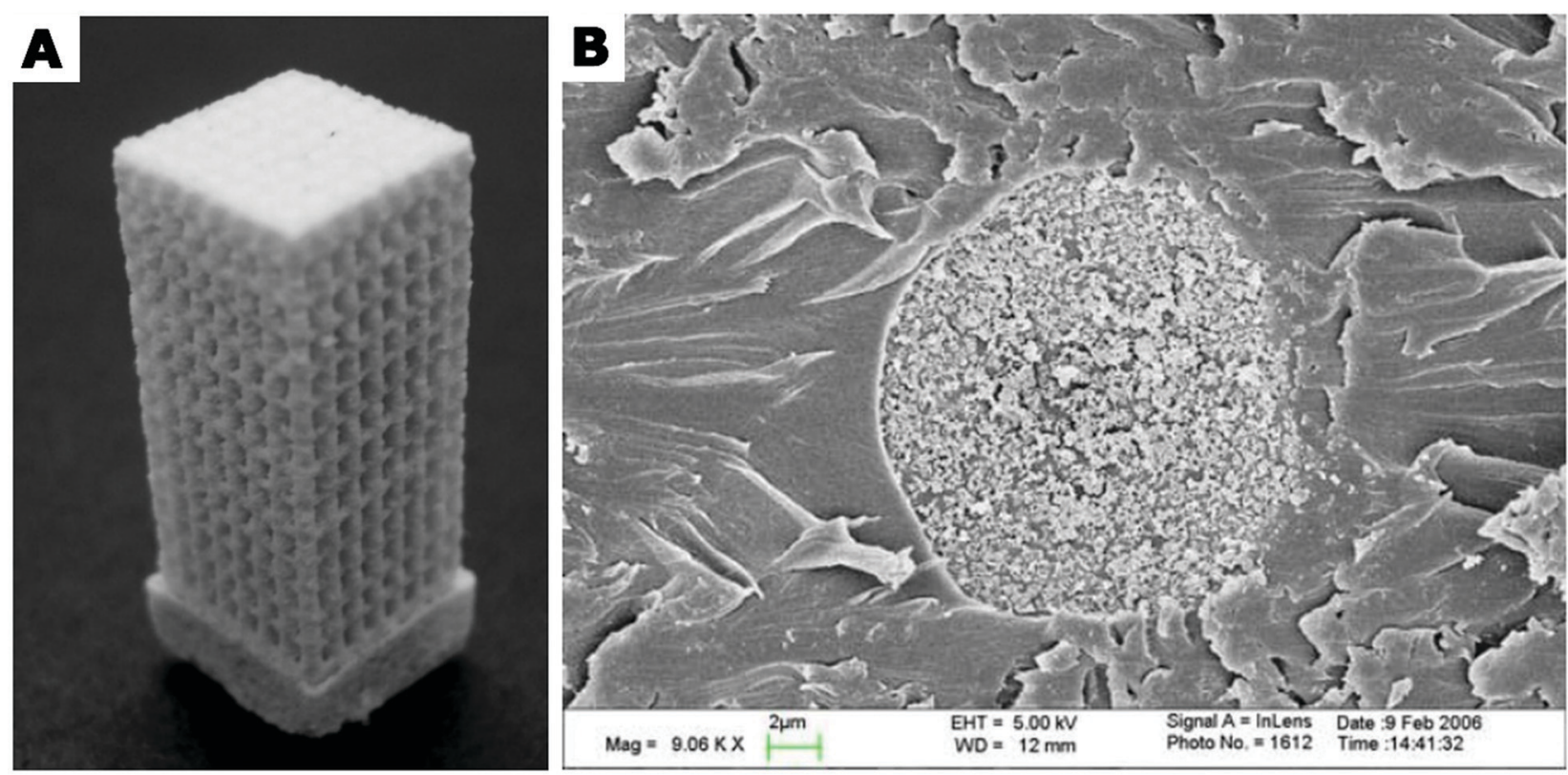

Fig. 15 (A) A composite porous scaffold sintered from PLA composite microspheres loaded with carbonated hydroxyapatite (CHAp) nanoparticles via selective laser sintering technique. (B) Scanning electron microscopy (SEM) image of a cross-section of PLA/CHAp composite microsphere. The microsphere cross section was obtained by embedding the microsphere in epoxy resin and sectioning with a microtome. Part (A): Copyright $(\mathrm{C} 2007$ Springer Science + Business Media, LLC. Adapted from ref. 201: https://doi.org/10.1007/s10856-007-3089-3 with permission from Springer Science + Business Media, LLC. Part (B): Copyright (C2007 Springer Nature. Adapted with permission from ref. 181: https://doi.org/10.1007/s10856-007-3156-9. 
nanoparticles loaded with drugs/biomolecules facilitating osteogenesis such as osteoinductive factors (e.g. bone morphogenetic proteins, BMPs, ${ }^{8-10}$ osteopontin, ${ }^{11}$ dexamethasone ${ }^{12}$ ), antimicrobial agents (e.g. $\mathrm{Ag},{ }^{13} \mathrm{CuO},{ }^{14} \mathrm{Se},{ }^{15}$ curcumin,${ }^{16-18}$ chlorhexidine, ${ }^{19,20}$ ), anti-inflammatory factors (e.g. curcumin, ${ }^{16-18,21}$ quercitrin ${ }^{22,23}$ ), drugs inhibiting bone resorption (e.g. bisphosphonates such as alendronate ${ }^{24-26}$ ) and others. This category of nanoparticles has been extensively investigated as bioactive components of bone implant materials such as bioinert synthetic polymers (e.g. polyethylenes, $\mathrm{PCL}$ ) or metallic substrates (titanium, aluminum oxide). ${ }^{203}$ Incorporating drug-loaded NPs into bone implants aims to enhance cell-implant interactions and cellular behaviors involved in osteogenesis and osteointegration ${ }^{8}$ or to prevent unwanted tissue response such as inflammation ${ }^{16-18,21}$ or bone resorption. ${ }^{24-26}$

The key advantage of drug immobilization in NPs is controlled sustained drug release due to the presence of a polymer matrix serving as a diffusion barrier for entrapped drug molecules. ${ }^{16}$ In contrast to direct immobilization of drugs onto the surface of bone implants (e.g. via physical adsorption or covalent conjugation), functionalization of grafts with drugeluting NPs does not require affinity between the drug and implant material and thus can be applied to much wider spectrum of bioactive agents regardless of their physicochemical properties. Such approach can also significantly increase drug loading efficiency providing more long-term therapeutic effect. ${ }^{16}$

The most widely used method for manufacturing of polymer NPs for drug/biomolecule delivery is nanoemulsion/solvent evaporation technique. In this approach, polymer (nanoparticle matrix material e.g. PLGA, ${ }^{17,24,25}$ poly(organophosphazene), ${ }^{204}$ $\mathrm{PLA}^{205}$ ) is dissolved in a volatile organic solvent such as chloroform, dichloromethane,${ }^{206}$ acetone,${ }^{25}$ DMSO,${ }^{25}$ ethyl acetate ${ }^{24}$ etc. Polymer/organic solvent solution (the oil phase) is dispersed in an aqueous phase containing a surfactant (for example by ultrasonication ${ }^{207}$ or high-speed homogenization) forming an $\mathrm{o} / \mathrm{w}$ nanoemulsion or double w/o/w nanoemulsion. ${ }^{206,207}$ Nanoemulsion droplets are subsequently converted into solid nanoparticles by evaporating the solvent from the polymer solution, ${ }^{112,206}$ which can be achieved by continuous magnetic stirring of nanoemulsion at room temperature under atmospheric or reduced pressure. During solvent evaporation, the nanodroplets can coalesce leading to uneven nanoparticle size distribution, which is one of the main limitations of this method. ${ }^{206}$ Furthermore, organic solvent present in polymer solution may lead to denaturation or loss of bioactivity of thermosensitive molecules encapsulated in the NPs. ${ }^{208}$ This method requires also the presence of surfactants, which have to be subsequently removed from the product before further use. ${ }^{206}$ Since surfactant removal procedures are time- and costconsuming and often do not provide sufficient purity, fabrication methods performed in the absence of surfactants such as salting-out technique are particularly desirable. In salting-out method, nanoemulsion is prepared by emulsification of polymer solution in organic solvent miscible with water (e.g. acetone) in an aqueous phase containing high concentration of salt (e.g. magnesium chloride, calcium chloride) or sucrose. ${ }^{206,209}$ Dilution of nanoemulsion with excess of water causes reduction in the salt/sucrose concentration in the continuous phase and migration of the solvent from the nanoemulsion droplets, which leads to precipitation of the polymer in the form of NPs.

Among drug-eluting polymer NPs for bone regeneration applications, biodegradable NPs (e.g. PLGA, ${ }^{8}$ PLGA/PCL ${ }^{212}$ chitosan ${ }^{10}$ ) loaded with bone morphogenetic proteins $(\mathrm{BMPs})^{8-10}$ are the most intensively studied. They are being explored as an alternative to current therapeutic approaches to healing traumatic bone injuries based on supra-physiological doses of BMP-2 introduced directly into the bone defect, which often lead to adverse side effects in the surrounding tissues such as ectopic bone formation, bone resorption and inflammation. ${ }^{65,210}$ BMP-loaded NPs have been investigated as both injectable drug delivery vehicles ${ }^{211,212}$ and bioactive components of bone implant materials. Biomaterials incorporating BMP-loaded nanoparticles can be obtained via surface functionalization, which can be achieved, for example, by embedding the biomaterial in a suspension of NPs in polymer/volatile solvent solution ${ }^{8}$ or spraying such suspension onto the implant surface ${ }^{10}$ followed by solvent evaporation. The former approach has been employed by Kim et al. to obtain 3D-printed hydroxyapatite scaffolds coated with PCL layer containing PLGA nanoparticles encapsulating BMP-2. ${ }^{8}$ Coating the implant with bioactive PLGA NPs/PCL layer provided long-term sustained release of BMP-2, which improved proliferation and osteogenic differentiation of mesenchymal stem cells (MSCs) seeded onto the implant and significantly accelerated healing of bone defects in experimental animals. Due to controlled sustained biomolecule release, bone implants decorated with BMP-eluting nanoparticles could resolve both the issue of short half-life of BMPs and the problem of adverse side effects associated with high BMP doses. ${ }^{210}$ Due to very small size, drug-loaded nanoparticles can also be suspended in hydrogel precursor gelling at body temperature and injected directly into the bone defect forming in situ gelling implant. ${ }^{18}$ Such administration route allows local delivery of the drug without its systemic side effects. Drug-loaded NPs may also be incorporated into bone implants in a spatially controlled manner via 3D-printing of nanoparticle suspension in a hydrogel precursor or cell-loaded bioink. ${ }^{8}$ Combining biomolecule-loaded NPs with 3D-printing technology $y^{8,213}$ is considered one of the most promising strategies in bone tissue engineering. It is anticipated that this technology will allow recreating tissue-specific composition and spatial distribution of multiple biomolecules involved in osteogenesis within bone tissue constructs and enable their spatially and temporary controlled sequential release mimicking biomolecule release pattern occurring in vivo.

\section{Fabrication of bone-targeting nanoparticles}

Recently, many efforts have been devoted to developing bonetargeting nanoparticles able to bind specifically to bone. This type of NPs may increase therapeutic efficiency and limit adverse side effects of released drugs on other tissues/organs due to accumulation at the target site and local drug delivery. ${ }^{214}$ Bone-targeting NPs are typically obtained by modification with compounds containing functional groups with high affinity 
to moieties present in the bone tissue such as $\mathrm{Ca}^{2+}$ ions. An example of such compounds is bisphosphonates (BP), comprising two $\mathrm{Ca}^{2+}$-binding phosphonate groups (P-C-P) in their molecules. $^{215}$ Among bisphosphonates, alendronate has emerged as a very promising agent for functionalization of NPs. ${ }^{24,25,204}$ Alendronate (ALN) is a drug approved by the FDA for clinical use in osteoporosis treatment. Its anti-osteoporotic effect is based on suppression of bone resorption through inhibition of osteoclast activity. ${ }^{216}$ ALN is also able to bind to hydroxyapatite (both natural and synthetic) via multiple $\mathrm{Ca}^{2+}$ ions present in its molecules $\left(\mathrm{Ca}_{10}\left(\mathrm{PO}_{4}\right)_{6}(\mathrm{OH})_{2}\right)$. Furthermore, when ALN-functionalized hydroxyapatite nanoparticles are incorporated into bone implants, they act as "anchors" strengthening interaction between the implant and the host tissue. $^{16,17}$ Therefore, functionalization of NPs with ALN yields three-functional delivery vehicles capable of targeting bone, inhibiting bone resorption and anchoring the implant to the host bone. For that reason, ALN has been broadly applied for functionalization of nanoparticles for bone regeneration applications including inorganic (e.g. hydroxyapatite, ${ }^{26} \mathrm{Fe}_{3} \mathrm{O}_{4}{ }^{217}$ clay $\left.^{218}\right)$ and polymer (e.g. poly( $\gamma$-benzyl-L-glutamate) ${ }^{17}$ poly(lacticco-glycolic acid ${ }^{24,25}$ ) nanoparticles. The majority of research in this area has been focused on PLGA nanoparticles, ${ }^{17,24,25}$ which have been approved by the FDA for use in drug delivery due to sustained drug release, low toxicity and biocompatibility. ${ }^{53}$ ALNmodified PLGA nanospheres are typically obtained via previously described nanoemulsion/solvent evaporation technique. ${ }^{17,24,25}$ This type of NPs has been shown to be non-cytotoxic, haemocompatible, biocompatible and suitable for intravenous administration. ${ }^{25}$ When injected intravenously, ALN-modified PLGA nanospheres have been shown to reach the bone much faster compared to control nanospheres (non-conjugated with ALN) and accumulate in the bones of experimental animals. ${ }^{24}$ ALN-NPs were also retained in the bones for longer periods of time than control nanoparticles, which translated to significantly improved therapeutic outcome. ${ }^{24}$ Unfortunately, ALN is a rare example of a drug that can act both as a therapeutic agent and bone-targeting ligand. To provide bone-targeted delivery of drugs without innate affinity to bone, other strategies have been proposed. For example, bone-targeting drug-loaded NPs have been obtained by introducing phosphonate groups into surfactants used during nanoparticle manufacturing. Zhang et al. have proposed conjugating a bisphosphonate (pamidronate) to the terminal hydroxyl group of a non-ionic surfactant Brij 78, which was subsequently used for fabrication of nano-formulations (such as lipid NPs, hydrogel PLGA NPs and oil-in-water nanoemulsions) for bone-targeted delivery of curcumin. ${ }^{16}$ Curcumin has multiple biological effects including suppressive effect on bone resorption, ${ }^{219}$ anti-inflammatory, ${ }^{21}$ analgesic, antioxidant ${ }^{18}$ and antimicrobial activity. ${ }^{220}$ Therefore, curcumin-eluting NPs hold a lot of promise as bioactive components of multifunctional bone implants that could potentially resolve the issues of implantrelated infections, pain and inflammation. ${ }^{18,21}$ Kasinathan and co-workers developed an injectable in situ gelling implant based on curcumin-loaded PCL nanoparticles suspended in PLGA sol gelling upon contact with phosphate buffer of physiological $\mathrm{pH}\left(\mathrm{pH}\right.$ 7.4). ${ }^{18}$ The resulting NPs-loaded gel has been demonstrated to release curcumin in a sustained manner over the period of 7 days in vitro and exert a substantially improved anti-tumor effect in mice compared to plain curcumin administered via intraperitoneal injection. ${ }^{18}$ Zambrano et al. have further confirmed therapeutic potential of injectable curcumin-loaded PLGA nanoparticles for local treatment of inflammation and inhibition of bone resorption in animal model of periodontal disease. ${ }^{21}$ Since implant-related infections and inflammation are one of the leading causes of bone implant failure, functionalization of bone substitute materials with curcumin-loaded NPs may contribute to significant improvement in their in vivo performance. ${ }^{21}$ Due to local drug release, this type of implants can also eliminate systemic side effects of drugs routinely administered in the postoperative period such as antibiotics, analgesics and anti-inflammatory drugs. ${ }^{221,222}$

\section{Challenges \& outlook}

Despite growing number of studies on bone implant materials functionalized with nanoparticles obtained via nanoemulsion technology, they have not yet reached the clinic and still remain at in vitro ${ }^{18,199}$ or animal testing stage. ${ }^{18,21}$ However, several bone substitute materials functionalized with nanoparticles fabricated via other techniques are currently on the market. Commercially available bone implant materials are based on ceramic nanoparticles, either hydroxyapatite nanocrystals (e.g. Ostim ${ }^{\circledR}$ injectable bone filling manufactured by Osartis, Germany or PerOssal ${ }^{\circledR}$ bone substitute by aap Implantate AG, Germany) or beta-tricalcium phosphate nanocrystals (e.g. Vitoss ${ }^{\circledR}$ Synthetic Cancellous Bone Void Filler by Orthovita/ Stryker, USA). ${ }^{23,224}$ These materials have been shown to be biocompatible, ${ }^{224}$ yet some questions remain about their longterm persistence in the body and their potential chronic toxicity. Key safety concerns are associated with the release of nanoparticles from implant material over time due to its mechanical wear or matrix material degradation, which may lead to unwanted effects in the surrounding tissues such as nanoparticle-induced inflammatory response, periprosthetic osteolysis and implant loosening. ${ }^{225-227}$ Due to high surfacearea-to-volume ratio nanoparticles are more biologically active compared to their micron-sized counterparts. As a result, once released from the implant, they may be able to induce much more potent adverse effects in the host. In addition, nanodimensions open up the possibility of nanoparticle migration to distant locations in the body and crossing biological barriers such as the blood-brain barrier ${ }^{228,229}$ and endothelium, ${ }^{230}$ as well as cellular and intracellular membranes, which gives them access to various cellular compartments including the nucleus. ${ }^{231}$ In vitro studies confirm that hydroxyapatite nanoparticles are easily taken up by cells, ${ }^{232,233}$ where they can exert an array of deleterious effects such as alterations in DNA structure, ${ }^{234}$ chromosome aberrations, ${ }^{235,236}$ cell membrane damage, production of reactive oxygen species/inflammatory cytokines $^{237-241}$ and apoptosis. ${ }^{242,243}$ The extent of nano- 
hydroxyapatite cytotoxicity is strongly related to nanoparticle shape and crystallinity with low crystalline, needle-shaped crystals being the most cytotoxic. ${ }^{241}$ Needle-shaped hydroxyapatite nanoparticles show also higher tendency to penetrate through biological barriers such as mucus membranes, as demonstrated by in vitro studies on models of mucosa-like human corneal epithelial tissue. ${ }^{244}$ For these reasons, needleshaped hydroxyapatite nanoparticles are of particular concern in relation to their systemic availability and chronic toxicity. The ability of hydroxyapatite NPs to pass through biological barriers has been also shown in a number of animal studies. Hydroxyapatite nanoparticles administered intravenously, ${ }^{245-247}$ intraperitoneally $^{248}$ or orally ${ }^{249}$ have been demonstrated to migrate and accumulate in the liver, kidneys and lungs. ${ }^{245,247-249}$ It has also been found that once they reached those organs, they induced multiple histopathological changes including degeneration of nephric tubule epithelium in the kidneys, ${ }^{245}$ degeneration of hepatic adipose tissue, ${ }^{249}$ inflammatory cell infiltration, ${ }^{249}$ necrosis and apoptosis, ${ }^{245,248}$ leading to elevation of tumor necrosis factor- $\alpha$ (TNF- $\alpha)^{239}$ in the serum. Pathomorphological changes in the liver translated to increased serum levels of hepatic enzymes including alanine aminotransferase (ALT), alkaline phosphatase (ALP) and aspartate aminotransferase (AST). ${ }^{247,249}$ It is worth noting that the above effects have been reported for relatively high doses of nanohydroxyapatite (10.0-33.3 mg per $\mathrm{kg}$ body weight $\mathrm{t}^{245,248}$ ) administered in a free (non-immobilized) form. Therefore, the informative value of these studies on in vivo toxicity of nano-HAp immobilized in composite bone implants is limited. It is likely that nano-hydroxyapatite particles released from an implant would not achieve sufficient concentration to elicit those effects. On the other hand, these findings strongly indicate that injectable therapies based on non-immobilized hydroxyapatite nanoparticles administered intravenously (e.g. bone-targeting $\mathrm{NPs}^{24}$ ) should be treated with particular caution in terms of nanoparticle migration/ accumulation in the body. Besides the issue of NPs migration, in case of nano-hydroxyapatite administered intravenously, there is growing concern about nanoparticle-induced haemolysis ${ }^{250}$ and aggregation of the red blood cells in the blood vessels, ${ }^{251}$ which poses a serious risk of vessel occlusion and thrombotic events. It has been also shown that HAp NPs can accumulate and deposit in the blood vessels similarly to cholesterol, leading to artery calcification and atherosclerosis. ${ }^{252}$

The safety of the second category of NPs fabricated via nanoemulsion technology - polymer NPs for drug/biomolecule delivery - also remains controversial. Biodegradable polymers typically used for manufacturing of this type of NPs (e.g. PLGA, PLA, PCL) are considered biocompatible and have been approved by the FDA for use in drug delivery and other biomedical applications. ${ }^{253}$ However, the distinctive physicochemical properties of nanoparticles related to their small size and high surface-area-to-volume ratio make it impossible to extrapolate the toxicity data of the raw material to polymer NPs. Although the fate of polymer NPs in the body is still not well understood, numerous in vitro studies demonstrate that they readily cross cellular membranes and are uptaken by cells. ${ }^{254,255}$ Cytotoxicity data also indicates that polymer NPs can cause cell membrane damage, ${ }^{256}$ alter DNA structure ${ }^{257}$ and induce production of inflammatory cytokines ${ }^{258,259}$ and reactive oxygen species in the cells. ${ }^{259-261}$ Further safety concerns are associated with the ability of polymer NPs to cross biological barriers (e.g. brain-blood barrier ${ }^{228,229}$ and bloodretina barrier ${ }^{256}$ ), migrate via the circulatory and lymphatic systems and accumulate in the distant lymph nodes ${ }^{262,263}$ or organs such as liver, ${ }^{228}$ spleen, lungs, bone marrow, ${ }^{264}$ kidney, heart and brain. ${ }^{228}$ Despite this fact, polymer NPs have not been demonstrated to exhibit significant in vivo toxicity in terms of pathomorphological changes in the target organs even at high doses administered intravenously ${ }^{265-267}$ or orally. ${ }^{228,260,268}$ In order to fully answer the question whether and to what extent nanoparticles used for bone regeneration applications are safe in the long-term, more data concerning their in vivo behavior and potential chronic toxicity is necessary.

\section{Conclusions}

Nanoemulsion technology has proven a valuable tool for fabrication of nanoparticles for bone regeneration applications. Combining nanoemulsification techniques with hydroxyapatite synthesis has enabled manufacturing of high-quality, monodisperse, agglomerate-free nanohydroxyapatite powders of significantly improved osteoinductive and mechanical properties. Polymer nanoparticles formulated via nanoemulsion technology have been extensively researched as bioactive components of orthopaedic implants providing sustained local delivery of drugs such as bone morphogenetic proteins, antimicrobial, antiinflammatory and anti-osteoporotic agents. Further advances have been made with the development of bone-targeting nanoparticles with high affinity to bone. As a result, in the recent years bone implant materials have progressed from bioinert bone substitutes serving merely as weight-bearing prostheses to multifunctional systems able to actively interact with the host tissue and stimulate new bone formation. The emergence of advanced tissue engineering techniques such as 3D-bioprinting has allowed incorporating nanoparticles into biomimetic bone tissue constructs in a spatially controlled manner providing tissue-specific distribution of bioactive molecules. Despite these significant advances, so far nanoparticles obtained via nanoemulsion technology have not reached the clinic and in the vast majority of cases remain at in vitro or animal testing stage. The main issues impeding clinical translation of these NPs are biocompatibility and safety concerns related to their very small size and ability to pass through biological barriers such as blood-brain barrier and cell membranes. The challenge that still needs to be addressed before this category of NPs can be implemented on a larger scale is scaling up of nanoemulsionbased methods for nanoparticle fabrication. More studies exploring in vivo behavior of nanoparticles, particularly in the long term, are also necessary to allow further progress in this field.

\section{Author contributions}

Barbara Kupikowska-Stobba: conceptualization, writing - original draft, visualization, writing - review \& editing. Mirosław Kasprzak: 
conceptualization, writing - original draft, visualization, supervision.

\section{Conflicts of interest}

There are no conflicts of interest to declare.

\section{Acknowledgements}

Funding for the present work was provided by the Foundation for Polish Science financed by the European Union under the European Regional Development Fund within the framework of the project "Multifunctional biologically active composites for applications in regenerative medicine of bone" (POIR.04.04.0000-16D7/18) carried out within the TEAM-NET programme. The authors would like to thank Dr Vlad Dinu, Assistant Professor, School of Bioscience, University of Nottingham, UK for his constructive feedback on our manuscript.

\section{References}

1 H. S. Sohn and J. K. Oh, Biomater. Res., 2019, 23, 9.

2 T. J. Blokhuis, in Bone Substitute Biomaterials, ed. K. Mallick, Elsevier Ltd., 2014, pp. 80-92.

3 G. Chandra and A. Pandey, Biocybern. Biomed. Eng., 2020, 40, 596-610.

4 W. R. Moore, S. E. Graves and G. I. Bain, ANZ J. Surg., 2001, 71, 354-361.

5 A. L. Ladd and K. Wirsing, Princ. Pract. Wrist Surg., 2009, 395, 277-287.

6 R. R. Betz, Orthopedics, 2002, 25, S561-S570.

7 P. Kazimierczak and A. Przekora, Coatings, 2020, 10, 971.

8 B. S. Kim, S. S. Yang and C. S. Kim, Colloids Surf., B, 2018, 170, 421-429.

9 L. Wang, W. Xu, Y. Chen and J. Wang, Sci. Rep., 2019, 9, 18175.

10 N. Poth, V. Seiffart, G. Gross, H. Menzel and W. Dempwolf, Biomolecules, 2015, 5, 3-19.

11 T. Jensen, J. Baas, A. Dolathshahi-Pirouz, T. Jacobsen, G. Singh, J. V. Nygaard, M. Foss, J. Bechtold, C. Bünger, F. Besenbacher and K. Søballe, J. Biomed. Mater. Res., Part A, 2011, 99, 94-101.

12 J. M. Oliveira, R. A. Sousa, N. Kotobuki, M. Tadokoro, M. Hirose, J. F. Mano, R. L. Reis and H. Ohgushi, Biomaterials, 2009, 30, 804-813.

13 S. Sivolella, E. Stellini, G. Brunello, C. Gardin, L. Ferroni, E. Bressan and B. Zavan, J. Nanomater., 2012, 2012, 975842.

14 F. Parnia, J. Yazdani, V. Javaherzadeh and S. Maleki Dizaj, J. Pharm. Pharm. Sci., 2017, 20, 148-160.

15 C. Vaquette, N. Bock and P. A. Tran, ACS Appl. Mater. Interfaces, 2020, 12, 55638-55648.

16 J. Zhang, X. Liu, T. Deng, P. Yao, H. Song, S. Zhou and W. Yan, J. Nanomater., 2015, 2015, 393968.

17 L. De Miguel, M. Noiray, G. Surpateanu, B. I. Iorga and G. Ponchel, Int. J. Pharm., 2014, 460, 73-82.
18 N. Kasinathan, M. Amirthalingam, N. D. Reddy, H. V. Jagani, S. M. Volety and J. V. Rao, Drug Delivery, 2016, 23, 1007-1015.

19 W. Fan, Y. Li, Q. Sun, T. Ma and B. Fan, J. Nanobiotechnol., 2016, 14, 72 .

20 N. J. Wood, H. F. Jenkinson, S. A. Davis, S. Mann, D. J. O'Sullivan and M. E. Barbour, J. Mater. Sci.: Mater. Med., 2015, 26, 201.

21 L. M. G. Zambrano, D. A. Brandao, F. R. G. Rocha, R. P. Marsiglio, I. B. Longo, F. L. Primo, A. C. Tedesco, M. R. Guimaraes-Stabili and C. Rossa, Sci. Rep., 2018, 8, 6652.

22 S. K. Wong, K. Y. Chin and S. Ima-Nirwana, Int. J. Mol. Sci., 2020, 21, 6448.

23 N. Ahmad, V. T. Banala, P. Kushwaha, A. Karvande, S. Sharma, A. K. Tripathi, A. Verma, R. Trivedi and P. R. Mishra, RSC Adv., 2016, 6, 97613-97628.

24 S. I. Thamake, S. L. Raut, Z. Gryczynski, A. P. Ranjan and J. K. Vishwanatha, Biomaterials, 2012, 33, 7164-7173.

25 E. Cenni, D. Granchi, S. Avnet, C. Fotia, M. Salerno, D. Micieli, M. G. Sarpietro, R. Pignatello, F. Castelli and N. Baldini, Biomaterials, 2008, 29, 1400-1411.

26 S. J. Hwang, J. S. Lee, T. K. Ryu, R. H. Kang, K. Y. Jeong, D. R. Jun, J. M. Koh, S. E. Kim and S. W. Choi, Macromol. Res., 2016, 24, 623-628.

27 D. J. McClements, Soft Matter, 2012, 8, 1719-1729.

28 T. Tadros, P. Izquierdo, J. Esquena and C. Solans, Adv. Colloid Interface Sci., 2004, 108-109, 303-318.

29 S. Zhang, S. Ding, J. Yu, X. Chen, Q. Lei and W. Fang, Langmuir, 2015, 31, 12161-12169.

30 N. Vlachy, D. Touraud, J. Heilmann and W. Kunz, Colloids Surf., B, 2009, 70, 278-280.

31 A. W. Khan, S. Kotta, S. H. Ansari, R. K. Sharma and J. Ali, Expert Opin. Drug Delivery, 2012, 9, 1305-1317.

32 S. Vieira, S. Vial and J. M. Oliveira, Biotechnol. Prog., 2017, 33, 590-611.

33 J. G. Lyons, M. A. Plantz, W. K. Hsu, E. L. Hsu and S. Minardi, Front. Bioeng. Biotechnol., 2020, 8, 922.

34 G. G. Walmsley, A. McArdle, R. Tevlin, A. Momeni, D. Atashroo, M. S. Hu, A. H. Feroze, V. W. Wong, P. H. Lorenz, M. T. Longaker and D. C. Wan, Nanomedicine, 2015, 11, 1253-1263.

35 A. Tautzenberger, A. Kovtun and A. Ignatius, Int. J. Nanomed., 2012, 7, 4545-4557.

36 N. Monteiro, A. Martins, R. L. Reis and N. M. Neves, Regener. Ther., 2015, 1, 109-118.

37 M. E. Marti, A. D. Sharma, D. S. Sakaguchi and S. K. Mallapragada, in Nanomaterials in Tissue Engineering: Fabrication and Applications, ed. A. K. Gaharwar, S. Sant, M. J. Hancock and S. A. Hacking, Woodhead Publishing Limited, 2013, pp. 275-301.

38 D. R. Amin, E. Sink, S. P. Narayan, M. Abdel-Hafiz, L. Mestroni and B. Peña, Molecules, 2020, 25, 5189.

39 C. Chu, J. Deng, L. Liu, Y. Cao, X. Wei, J. Li and Y. Man, RSC Adv., 2016, 6, 90856-90872.

40 M. Fathi-Achachelouei, H. Knopf-Marques, C. E. Ribeiro da Silva, J. Barthès, E. Bat, A. Tezcaner and N. E. Vrana, Front. Bioeng. Biotechnol., 2019, 7, 113. 
41 A. Szcześ, L. Hołysz and E. Chibowski, Adv. Colloid Interface Sci., 2017, 249, 321-330.

42 H. L. Kim, G. Y. Jung, J. H. Yoon, J. S. Han, Y. J. Park, D. G. Kim, M. Zhang and D. J. Kim, Mater. Sci. Eng., C, 2015, 54, 20-25.

43 D. Arcos and M. Vallet-Regí, J. Mater. Chem. B, 2020, 8, 1781-1800.

44 M. Sharafipour, H. Oveisi and A. Meshkini, J. Biomed. Mater. Res., Part A, 2020, 108, 882-894.

45 M. D. Calasans-Maia, B. R. Melo, A. T. N. N. Alves, R. F. B. Resende, R. S. Louro, S. C. Sartoretto, J. M. Granjeiro and G. G. Alves, J. Appl. Oral Sci., 2015, 23, 599-608.

46 S. L. Aktuğ, S. Durdu, E. Yalçın, K. Çavuşoğlu and M. Usta, Mater. Sci. Eng., C, 2017, 71, 1020-1027.

47 H.-J. Lo, G. Rau, Y.-J. Kuo, C. J. Liao, C.-H. Yang and Y.-H. Tsuang, J. Orthop. Surg., 2009, 26, 111-119.

48 X. Yang, Y. Li, X. Liu, R. Zhang and Q. Feng, Stem Cells Int., 2018, 2018, 2036176.

49 L. Lin, K. L. Chow and Y. Leng, J. Biomed. Mater. Res., Part A, 2009, 89, 326-335.

50 L. Cheng, F. Ye, R. Yang, X. Lu, Y. Shi, L. Li, H. Fan and H. Bu, Acta Biomater., 2010, 6, 1569-1574.

51 M. I. Hassan, N. Sultana and S. Hamdan, J. Nanomater., 2014, 2014, 573238.

52 Y. M. Baba Ismail, I. Wimpenny, O. Bretcanu, K. Dalgarno and A. J. El Haj, J. Biomed. Mater. Res., Part A, 2017, 105A, 1775-1785.

53 I. Bala, S. Hariharan and M. N. V. Ravi Kumar, Crit. Rev. Ther. Drug Carrier Syst., 2004, 21, 387-422.

54 Y. M. Khan, D. S. Katti and C. T. Laurencin, J. Biomed. Mater. Res., Part A, 2004, 69, 728-737.

55 M. Kikuchi, Y. Koyama, K. Takakuda, H. Miyairi, N. Shirahama and J. Tanaka, J. Biomed. Mater. Res., 2002, 62, 265-272.

56 T. Chae, H. Yang, V. Leung, F. Ko and T. Troczynski, J. Mater. Sci.: Mater. Med., 2013, 24, 1885-1894.

57 J. Qian, W. Xu, X. Yong, X. Jin and W. Zhang, Mater. Sci. Eng., C, 2014, 36, 95-101.

58 J. Norton, K. R. Malik, J. A. Darr and I. U. Rehman, Adv. Appl. Ceram., 2006, 105, 113-139.

59 T. Janicki, A. Sobczak-Kupiec, P. Skomro and Z. Wzorek, Acta Bioeng. Biomech., 2012, 14, 31-38.

60 P. Malmberg and H. Nygren, Proteomics, 2008, 8, 3755-3762.

61 X. Gao, C. Dai, W. Liu, Y. Liu, R. Shen, X. Zheng, K. Duan, J. Weng and S. Qu, J. Mater. Sci.: Mater. Med., 2017, 28, 83.

62 S. V. Dorozhkin, Acta Biomater., 2010, 6, 715-734.

63 V. Ogay, E. A. Mun, G. Kudaibergen, M. Baidarbekov, K. Kassymbek, Z. Zharkinbekov and A. Saparov, Polymers, 2020, 12, 2881.

64 A. Peeters, G. Putzeys and L. Thorrez, J. Bone Jt. Infect., 2019, 4, 245-253.

65 K. S. Cahill, J. H. Chi, A. Day and E. B. Claus, JAMA, 2009, 302, 58-66.

66 K. Gurpret and S. K. Singh, Indian J. Pharm. Sci., 2018, 80, 781-789.
67 T. F. Tadros, in An Introduction to Surfactants, ed. T. F. Tadros, De Gruyter, 2014, pp. 135-152.

68 F. Goodarzi and S. Zendehboudi, Can. J. Chem. Eng., 2019, 97, 281-309.

69 R. L. McMullen, M. Gorcea and S. Chen, in Handbook of Formulating Dermal Applications: A Definitive Practical Guide, ed. N. Dayan, Scrivener Publishing LLC., 2016, pp. 129-153.

70 T. F. Tadros, in Emulsion Formation and Stability, ed. T. F. Tadros, Wiley-VCH Verlag GmbH \& Co. KGaA, 1st edn, 2013, pp. 1-75.

71 S. L. Ee, X. Duan, J. Liew and Q. D. Nguyen, Chem. Eng. J., 2008, 140, 626-631.

72 A. Gupta, H. B. Eral, T. A. Hatton and P. S. Doyle, Soft Matter, 2016, 12, 2826-2841.

73 D. J. McClements, Crit. Rev. Food Sci. Nutr., 2007, 47, 611-649.

74 R. Botet, J. Phys.: Conf. Ser., 2012, 352, 012047.

75 Q. Huang, H. Yu and Q. Ru, J. Food Sci., 2010, 75, R50-R57.

76 M. Koroleva, T. Nagovitsina and E. Yurtov, Phys. Chem. Chem. Phys., 2018, 20, 10369-10377.

77 R. Parveen, S. Baboota, J. Ali, A. Ahuja and S. Ahmad, J. Pharm. BioAllied Sci., 2015, 7, 321-324.

78 T. Sheth, S. Seshadri, T. Prileszky and M. E. Helgeson, Nat. Rev. Mater., 2020, 5, 214-228.

79 C. Liu, M. Li, R. Han, J. Li and C. Liu, J. Dispersion Sci. Technol., 2016, 37, 333-344.

80 C. Qian and D. J. McClements, Food Hydrocolloids, 2011, 25, 1000-1008.

81 L. Mao, J. Yang, D. Xu, F. Yuan and Y. Gao, J. Dispersion Sci. Technol., 2010, 31, 986-993.

82 C. P. Tan and M. Nakajima, Food Chem., 2005, 92, 661-671.

83 D. J. McClements, Food Emulsions. Principles, Practices, and Techniques, CRC Press, 2nd edn, 2004.

84 D. H. Oh, P. Balakrishnan, Y. K. Oh, D. D. Kim, C. S. Yong and H. G. Choi, Int. J. Pharm., 2011, 404, 191-197.

85 J. Rao and D. J. McClements, J. Agric. Food Chem., 2011, 59, 5026-5035.

86 H. Schubert and R. Engel, Chem. Eng. Res. Des., 2004, 82, 1137-1143.

87 L. Mao, D. Xu, J. Yang, F. Yuan, Y. Gao and J. Zhao, Food Technol. Biotechnol., 2009, 47, 336-342.

88 S. M. Jafari, E. Assadpoor, Y. He and B. Bhandari, Food Hydrocolloids, 2008, 22, 1191-1202.

89 A. Håkansson, C. Trägårdh and B. Bergenståhl, Chem. Eng. Sci., 2009, 64, 2915-2925.

90 Y. T. Hu, Y. Ting, J. Y. Hu and S. C. Hsieh, J. Food Drug Anal., 2017, 25, 16-26.

91 K. Rahn-Chique, A. M. Puertas, M. S. Romero-Cano, C. Rojas and G. Urbina-Villalba, Adv. Colloid Interface Sci., 2012, 178, 1-20.

92 H. H. Tayeb and F. Sainsbury, Nanomedicine, 2018, 13, 2507-2525.

93 Y. Zheng, M. Zheng, Z. Ma, B. Xin, R. Guo and X. Xu, in Polar Lipids, ed. M. U. Ahmad and X. Xu, Biology, Chemistry, and Technology, Elsevier Inc., 2015, pp. 215-243. 
94 I. Kralova and J. Sjöblom, J. Dispersion Sci. Technol., 2009, 30, 1363-1383.

95 N. Ng and M. A. Rogers, in Encyclopedia of Food Chemistry, ed. L. Melton, F. Shahidi and P. Varelis, Elsevier Inc., 2019, pp. 276-282.

96 A. Witthayapanyanon, J. H. Harwell and D. A. Sabatini, J. Colloid Interface Sci., 2008, 325, 259-266.

97 M. J. Rosen and J. T. Kunjappu, Surfactants and Interfacial Phenomena, John Wiley \& Sons, Inc., 4th edn, 2012.

98 P. Taylor, J. Salager, J. Bullón, A. Pizzino, M. RondónGonzález and L. Tolosa, in Encyclopedia of Surface and Colloid Science, ed. P. Somasundaran, Taylor \& Francis, 2nd edn, 2010, pp. 1-16.

99 Handbook of Detergents, Part A: Properties, ed. G. Broze, CRC Press, 1st edn, 1999.

100 E. J. Acosta, J. S. Yuan and A. S. Bhakta, J. Surfactants Deterg., 2008, 11, 145-158.

101 P. Izquierdo, J. Esquena, T. F. Tadros, C. Dederen, M. J. Garcia, N. Azemar and C. Solans, Langmuir, 2002, 18, 26-30.

102 L. Salvia-Trujillo, R. Soliva-Fortuny, M. A. Rojas-Graü, D. J. McClements and O. Martín-Belloso, Annu. Rev. Food Sci. Technol., 2017, 8, 439-466.

103 Colloidal Suspension Rheology, ed. J. Mewis and N. J. Wagner, Cambridge University Press, 2011.

104 G. Chen and D. Tao, Fuel Process. Technol., 2005, 86, 499-508. 105 A. Forgiarini, J. Esquena, C. González and C. Solans, in Trends in Colloid and Interface Science XIV, ed. Buckin, Progress in Colloid and Polymer Science, Springer, Berlin, Heidelberg, 2000, vol. 115, pp. 36-39.

106 P. Izquierdo, J. Esquena, T. F. Tadros, J. C. Dederen, J. Feng, M. J. Garcia-Celma, N. Azemar and C. Solans, Langmuir, 2004, 20, 6594-6598.

107 Foundations of Colloid Science, ed. R. J. Hunter, Oxford University Press, 2nd edn, 2001.

108 Y. Takahashi and Y. Kondo, in Stimuli-Responsive Interfaces: Fabrication and Application, ed. T. Kawai and M. Hashizume, Springer, Singapore, 1st edn, 2017, pp. 5-17.

109 S. Li, F. Wang, Z. Yang, J. Xu, H. Liu, L. Zhang and W. Xu, Powder Technol., 2020, 359, 17-26.

110 F. Wang, X. Yu, Z. Yang, H. Duan, Z. Zhang and H. Liu, J. Phys. Chem. C, 2018, 122, 18995-19003.

111 A. Maali and M. T. H. Mosavian, J. Dispersion Sci. Technol., 2013, 34, 92-105.

112 N. Anton, J. P. Benoit and P. Saulnier, J. Controlled Release, 2008, 128, 185-199.

113 Y. Singh, J. G. Meher, K. Raval, F. A. Khan, M. Chaurasia, N. K. Jain and M. K. Chourasia, J. Controlled Release, 2017, 252, 28-49.

114 M. Stang, H. Schuchmann and H. Schubert, Eng. Life Sci., 2001, 1, 151-157.

115 J. B. Aswathanarayan and R. R. Vittal, Front. Sustain. Food Syst., 2019, 3, 95.

116 S. Schultz, G. Wagner, K. Urban and J. Ulrich, Chem. Eng. Technol., 2004, 27, 361-368.

117 M. Kumar, R. S. Bishnoi, A. K. Shukla and C. P. Jain, Prev. Nutr. Food Sci., 2019, 24, 225-234.
118 E. B. Souto, C. Anselmi, M. Centini and R. H. Müller, Int. J. Pharm., 2005, 295, 261-268.

119 O. Behrend, K. Ax and H. Schubert, Ultrason. Sonochem., 2000, 7, 77-85.

120 T. S. H. Leong, T. J. Wooster, S. E. Kentish and M. Ashokkumar, Ultrason. Sonochem., 2009, 16, 721-727.

121 S. Kentish, T. J. Wooster, M. Ashokkumar, S. Balachandran, R. Mawson and L. Simons, Innovative Food Sci. Emerging Technol., 2008, 9, 170-175.

122 K. Landfester, J. Eisenblätter and R. Rothe, J. Coat. Technol. Res., 2004, 1, 65-68.

123 S. G. Gaikwad and A. B. Pandit, Ultrason. Sonochem., 2008, 15, 554-563.

124 I. O. Ocampo-Salinas, D. I. Ellez-Medina, C. JimenezMartinez and G. Davila-Ortiz, Int. J. Environ. Agric. Biotechnol., 2016, 1, 646-662.

125 G. Modig, L. Nilsson, B. Bergenståhl and K. G. Wahlund, Food Hydrocolloids, 2006, 20, 1087-1095.

126 J. Floury, A. Desrumaux, M. A. V. Axelos and J. Legrand, Food Hydrocolloids, 2002, 16, 47-53.

127 M. R. Kasaai, G. Charlet, P. Paquin and J. Arul, Innovative Food Sci. Emerging Technol., 2003, 4, 403-413.

128 I. Solè, C. M. Pey, A. Maestro, C. González, M. Porras, C. Solans and J. M. Gutiérrez, J. Colloid Interface Sci., 2010, 344, 417-423.

129 N. Anton and T. F. Vandamme, Int. J. Pharm., 2009, 377, 142-147.

130 M. Pathak, in Nanotechnology Applications in Food: Flavor, Stability, Nutrition and Safety, ed. A. E. Oprea and A. M. Grumezescu, Elsevier Inc., 2017, pp. 87-106.

131 C. Jadhav, V. Kate and S. A. Payghan, J. Nanostruct. Chem., 2015, 5, 107-113.

132 C. Solans and I. Solé, Curr. Opin. Colloid Interface Sci., 2012, 17, 246-254.

133 P. Izquierdo, J. Feng, J. Esquena, T. F. Tadros, J. C. Dederen, M. J. Garcia, N. Azemar and C. Solans, J. Colloid Interface Sci., 2005, 285, 388-394.

134 D. J. McClements and J. Rao, Crit. Rev. Food Sci. Nutr., 2011, 51, 285-330.

135 A. Maestro, I. Solè, C. González, C. Solans and J. M. Gutiérrez, J. Colloid Interface Sci., 2008, 327, 433-439.

136 J. C. L. Liew, Q. D. Nguyen and Y. Ngothai, Asia-Pac. J. Chem. Eng., 2010, 5, 570-576.

137 A. Perazzo and V. Preziosi, in Nanoemulsions: Formulation, Applications, and Characterization, ed. S. M. Jafari and D. J. McClements, Academic Press, 1st edn, 2018, pp. 5376.

138 T. S. Dunstan, P. D. I. Fletcher and S. Mashinchi, Langmuir, 2012, 28, 339-349.

139 R. K. Thakur, C. Villette, J. M. Aubry and G. Delaplace, Colloids Surf., A, 2008, 315, 285-293.

140 S. M. Jafari, P. Paximada, I. Mandala, E. Assadpour and M. A. Mehrnia, in Nanoencapsulation Technologies for the Food and Nutraceutical Industries, ed. S. M. Jafari, Academic Press, 1st edn, 2017, pp. 36-73.

141 D. J. McClements, Soft Matter, 2011, 7, 2297-2316. 
142 K. Bouchemal, S. Briançon, E. Perrier and H. Fessi, Int. J. Pharm., 2004, 280, 241-251.

143 N. A. N. Azmi, A. A. M. Elgharbawy, S. R. Motlagh, N. Samsudin and H. M. Salleh, Processes, 2019, 7, 617.

144 M. Safaya and Y. C. Rotliwala, Mater. Today: Proc., 2020, 27, 454-459.

145 A. A. Date, N. Desai, R. Dixit and M. Nagarsenker, Nanomedicine, 2010, 5, 1595-1616.

146 A. W. Khan, S. Kotta, S. H. Ansari, R. K. Sharma and J. Ali, Drug Delivery, 2015, 22, 552-561.

147 M. Dahiya and P. Pandey, Int. J. Pharm. Integr. Life Sci., 2016, 4, 43-61.

148 S. Parveen, R. Misra and S. K. Sahoo, Nanomedicine, 2012, 8, 147-166.

149 Z. Urbán-Morlán, S. E. Mendoza-Elvira, R. S. HernándezCerón, S. Alcalá-Alcalá, H. Ramírez-Mendoza, A. CipriánCarrasco, E. Piñón-Segundo and D. Quintanar-Guerrero, J. Mex. Chem. Soc., 2015, 59, 173-180.

150 Y. Wang, P. Li, T. T.-D. Tran, J. Zhang and L. Kong, Nanomaterials, 2016, 6, 26.

151 S. Grandhi, A. Prameela Rani and R. Pathuri, Res. J. Pharm. Technol., 2018, 11, 2829-2835.

152 J. Feng, M. Roché, D. Vigolo, L. N. Arnaudov, S. D. Stoyanov, T. D. Gurkov, G. G. Tsutsumanova and H. A. Stone, Nat. Phys., 2014, 10, 606-612.

153 J. Feng, J. K. Nunes, S. Shin, J. Yan, Y. L. Kong, R. K. Prud'homme, L. N. Arnaudov, S. D. Stoyanov and H. A. Stone, Adv. Mater., 2016, 28, 4047-4052.

154 M. M. Villa, L. Wang, J. Huang, D. W. Rowe and M. Wei, J. Biomed. Mater. Res., Part B, 2015, 103, 243-253.

155 M. Prekajski, M. Mirković, B. Todorović, A. Matković, M. Marinović-Cincović, J. Luković and B. Matović, J. Eur. Ceram. Soc., 2016, 36, 1293-1298.

156 M. Prekajski, B. Jokić, A. Kalijadis, J. Maletaškić, N. Stanković, J. Luković and B. Matović, Process. Appl. Ceram., 2016, 10, 169-174.

157 M. P. Pileni, J. Phys. Chem., 1993, 97, 6961-6973.

158 G. K. Lim, J. Wang, S. C. Ng, C. H. Chew and L. M. Gan, Biomaterials, 1997, 18, 1433-1439.

159 G. K. Lim, J. Wang, S. C. Ng and L. M. Gan, Mater. Lett., 1996, 28, 431-436.

160 M. Cao, Y. Wang, C. Guo, Y. Qi and C. Hu, Langmuir, 2004, 20, 4784-4786.

161 A. Banerjee, A. Bandyopadhyay and S. Bose, Mater. Sci. Eng., C, 2007, 27, 729-735.

162 K. Suchanek, A. Bartkowiak, A. Gdowik, M. Perzanowski, S. Kac, B. Szaraniec, M. Suchanek and M. Marszałek, Mater. Sci. Eng., C, 2015, 51, 57-63.

163 L. T. Bang, S. Ramesh, J. Purbolaksono, Y. C. Ching, B. D. Long, H. Chandran and R. Othman, Mater. Des., 2015, 87, 788-796.

164 N. Jing, A. N. Zhou and Q. H. Xu, J. Hazard. Mater., 2018, 353, 89-98.

165 S. E. Cahyaningrum, N. Herdyastuty, B. Devina and D. Supangat, IOP Conf. Ser.: Mater. Sci. Eng., 2018, 299, 012039.
166 M. Biernat, Z. Jaegermann, P. Tymowicz-Grzyb and G. Konopka, Process. Appl. Ceram., 2019, 13, 57-64.

167 A. C. Tas, J. Am. Ceram. Soc., 2007, 90, 2358-2362.

168 O. V. Sinitsyna, A. G. Veresov, E. S. Kovaleva, Y. V. Kolen'ko, V. I. Putlyaev and Y. D. Tretyakov, Russ. Chem. Bull., 2005, 54, 79-86.

169 W. J. Shih, Y. F. Chen, M. C. Wang and M. H. Hon, J. Cryst. Growth, 2004, 270, 211-218.

170 M. G. S. Murray, J. Wang, C. B. Ponton and P. M. Marquis, J. Mater. Sci., 1995, 30, 3061-3074.

171 N. Y. Mostafa, Mater. Chem. Phys., 2005, 94, 333-341.

172 M. Eriksson, Y. Liu, J. Hu, L. Gao, M. Nygren and Z. Shen, J. Eur. Ceram. Soc., 2011, 31, 1533-1540.

173 N. A. S. Mohd Pu'ad, R. H. Abdul Haq, H. Mohd Noh, H. Z. Abdullah, M. I. Idris and T. C. Lee, Mater. Today: Proc., 2019, 29, 233-239.

174 H. C. Shum, A. Bandyopadhyay, S. Bose and D. A. Weitz, Chem. Mater., 2009, 21, 5548-5555.

175 T. Y. Podlipskaya and A. I. Bulavchenko, J. Struct. Chem., 2019, 60, 1133-1142.

176 A. Amani and M. Amani, J. Contemp. Med. Sci., 2015, 1, 1-6.

177 I. Ezekiel, S. R. Kasim, Y. M. B. Ismail and A. F. M. Noor, Ceram. Int., 2018, 44, 13082-13089.

178 M. N. Muhammad Syazwan and B. I. Yanny Marliana, Ceram. Int., 2019, 45, 14783-14788.

179 W. Amer, K. Abdelouahdi, H. R. Ramananarivo, M. Zahouily, A. Fihri, Y. Coppel, R. S. Varma and A. Solhy, Mater. Lett., 2013, 107, 189-193.

180 Y. Sun, G. Guo, D. Tao and Z. Wang, J. Phys. Chem. Solids, 2007, 68, 373-377.

181 W. Y. Zhou, M. Wang, W. L. Cheung, B. C. Guo and D. M. Jia, J. Mater. Sci.: Mater. Med., 2008, 19, 103-110.

182 A. Ethirajan, U. Ziener, A. Chuvilin, U. Kaiser, H. Cölfen and K. Landfester, Adv. Funct. Mater., 2008, 18, 2221-2227.

183 K. Mitri, C. Vauthier, N. Huang, A. Menas, C. RingardLefebvre, C. Anselmi, M. Stambouli, V. Rosilio, J. J. Vachon and K. Bouchemal, J. Pharm. Sci., 2012, 101, 4240-4247.

184 S. A. Galindo-Rodríguez, F. Puel, S. Briançon, E. Allémann, E. Doelker and H. Fessi, Eur. J. Pharm. Sci., 2005, 25, 357-367.

185 Y. Liu, C. Cheng, Y. Liu, R. K. Prud'homme and R. O. Fox, Chem. Eng. Sci., 2008, 63, 2829-2842.

186 D. L. Marchisio, L. Rivautella and A. A. Barresi, AIChE J., 2006, 52, 1877-1887.

187 F. Ganachaud and J. L. Katz, ChemPhysChem, 2005, 6, 209-216.

188 B. Kupikowska-Stobba and D. Lewińska, Biomater. Sci., 2020, 8, 1536-1574.

189 J. Chen, D. Huang, L. Wang, J. Hou, H. Zhang, Y. Li, S. Zhong, Y. Wang, Y. Wu and W. Huang, J. Colloid Interface Sci., 2020, 574, 162-173.

190 M. A. Vandelli, F. Rivasi, P. Guerra, F. Forni and R. Arletti, Int. J. Pharm., 2001, 215, 175-184.

191 A. Totaro, A. Salerno, G. Imparato, C. Domingo, F. Urciuolo and P. A. Netti, J. Tissue Eng. Regener. Med., 2017, 11, 1865-1875. 
192 S. Itoh, M. Kikuchi, Y. Koyama, K. Takakuda, K. Shinomiya and J. Tanaka, Biomaterials, 2002, 23, 3919-3926.

193 L. Gritsch, M. Maqbool, V. Mouriño, F. E. Ciraldo, M. Cresswell, P. R. Jackson, C. Lovell and A. R. Boccaccini, J. Mater. Chem. B, 2019, 7, 6109-6124.

194 Y. Chen, A. F. T. Mak, M. Wang, J. S. Li and M. S. Wong, J. Mater. Sci.: Mater. Med., 2008, 19, 2261-2268.

195 G. Wei and P. X. Ma, Biomaterials, 2004, 25, 4749-4757.

196 L. Jiang, Y. Li, C. Xiong, S. Su and H. Ding, ACS Appl. Mater. Interfaces, 2017, 9, 4890-4897.

197 P. Habibovic, Biomatter, 2014, 4, e27664.

198 M. Wang, Biomaterials, 2003, 24, 2133-2151.

199 Y. M. Baba Ismail, A. M. Ferreira, O. Bretcanu, K. Dalgarno and A. J. El Haj, Colloids Surf., B, 2017, 159, 445-453.

200 W. Y. Zhou, M. Wang and W. L. Cheung, in Advances in Diverse Industrial Applications of Nanocomposites, ed. B. Reddy, IntechOpen, 2011, pp. 203-230.

201 W. Y. Zhou, S. H. Lee, M. Wang, W. L. Cheung and W. Y. Ip, J. Mater. Sci.: Mater. Med., 2008, 19, 2535-2540.

202 W. Y. Zhou, M. Wang and W. L. Cheung, Key Eng. Mater., 2007, 334-335, 1221-1224.

203 J. F. Mano, R. A. Sousa, L. F. Boesel, N. M. Neves and R. L. Reis, Compos. Sci. Technol., 2004, 64, 789-817.

204 J. Vandorpe, E. Schacht, S. Stolnik, M. C. Garnett, M. C. Davies, L. Illum and S. S. Davis, Biotechnol. Bioeng., 1996, 52, 89-95.

205 Q. Li, K. Li, Q. Han, M. Wu and N. Zhang, Int. J. Clin. Exp. Med., 2020, 13, 4035-4041.

206 J. P. Rao and K. E. Geckeler, Prog. Polym. Sci., 2011, 36, 887-913.

207 U. Bilati, E. Allémann and E. Doelker, Pharm. Dev. Technol., 2003, 8, 1-9.

208 U. Bilati, E. Allémann and E. Doelker, AAPS PharmSciTech, 2005, 6, E594-E604.

209 Z. Zhang, D. W. Grijpma and J. Feijen, J. Controlled Release, 2006, 111, 263-270.

210 A. W. James, G. LaChaud, J. Shen, G. Asatrian, V. Nguyen, X. Zhang, K. Ting and C. Soo, Tissue Eng., Part B, 2016, 22, 284-297.

211 B. B. Seo, H. Choi, J. T. Koh and S. C. Song, J. Controlled Release, 2015, 209, 67-76.

212 A. H. Hassan, K. M. Hosny, Z. A. Murshid, A. Alhadlaq, A. Alyamani and G. Naguib, Drug Des., Dev. Ther., 2015, 9, 3599-3606.

213 K. H. Huang, Y. H. Lin, M. Y. Shie and C. P. Lin, J. Formosan Med. Assoc., 2018, 117, 879-887.

214 H. Cheng, A. Chawla, Y. Yang, Y. Li, J. Zhang, H. L. Jang and A. Khademhosseini, Drug Discovery Today, 2017, 22, 1336-1350.

215 V. Hengst, C. Oussoren, T. Kissel and G. Storm, Int. J. Pharm., 2007, 331, 224-227.

216 C. T. Leu, E. Luegmayr, L. P. Freedman, G. A. Rodan and A. A. Reszka, Bone, 2006, 38, 628-636.

217 M. S. Lee, C. M. Su, J. C. Yeh, P. R. Wu, T. Y. Tsai and S. L. Lou, Int. J. Nanomed., 2016, 11, 4583-4594.

218 H. Piao, M. H. Kim, M. Cui, G. Choi and J. H. Choy, J. Korean Med. Sci., 2019, 34, e37.
219 M. Hie, M. Yamazaki and I. Tsukamoto, Eur. J. Pharmacol., 2009, 621, 1-9.

220 B. B. Aggarwal and K. B. Harikumar, Int. J. Biochem. Cell Biol., 2009, 41, 40-59.

221 B. A. Cunha, Med. Clin. North Am., 2001, 85, 149-185.

222 S. Heta and I. Robo, Med. Sci., 2018, 6, 6.

223 K. Brannigan and M. Griffin, Open Orthop. J., 2017, 10, 808-823.

224 M. L. Etheridge, S. A. Campbell, A. G. Erdman, C. L. Haynes, S. M. Wolf and J. McCullough, Nanomedicine, 2013, 9, 1-14.

225 L. Zhang, E. M. Haddouti, K. Welle, C. Burger, K. Kabir and F. A. Schildberg, Int. J. Nanomed., 2020, 15, 6705-6720.

226 S. B. Goodman and J. Gallo, J. Clin. Med., 2019, 8, 2091.

227 K. Fox, P. A. Tran and N. Tran, ChemPhysChem, 2012, 13, 2495-2506.

228 B. Semete, L. Booysen, Y. Lemmer, L. Kalombo, L. Katata, J. Verschoor and H. S. Swai, Nanomedicine, 2010, 6, 662-671.

229 P. R. Lockman, R. J. Mumper, M. A. Khan and D. D. Allen, Drug Dev. Ind. Pharm., 2002, 28, 1-13.

230 S. Barua and S. Mitragotri, Nano Today, 2014, 9, 223-243.

231 W. H. De Jong and P. J. A. Borm, Int. J. Nanomed., 2008, 3, 133-149.

232 I. W. Bauer, S. P. Li, Y. C. Han, L. Yuan and M. Z. Yin, J. Mater. Sci.: Mater. Med., 2008, 19, 1091-1095.

233 L. Chen, J. M. Mccrate, J. C. M. Lee and H. Li, Nanotechnology, 2011, 22, 105708.

234 M. Banik and T. Basu, Dalton Trans., 2014, 43, 3244-3259.

235 H. Turkez, M. I. Yousef, E. Sönmez, B. Togar, F. Bakan, P. Sozio and A. D. Stefano, J. Appl. Toxicol., 2014, 34, 373-379.

236 V. Opačić-Galić, V. Petrović, S. Živković, V. Jokanović, B. Nikolić, J. Knežević-Vukčević and D. Mitić-Ćulafić, Int. Endod. J., 2013, 46, 506-516.

237 J. Xu, P. Xu, Z. Li, J. Huang and Z. Yang, J. Biomed. Mater. Res., Part A, 2012, 100, 738-745.

238 C. S. Geetha, N. S. Remya, K. B. Leji, S. Syama, S. C. Reshma, P. J. Sreekanth, H. K. Varma and P. V. Mohanan, Colloids Surf., B, 2013, 112, 204-212.

239 X. Liu and J. Sun, Int. J. Nanomed., 2014, 9, 1261-1273.

240 P. Laquerriere, A. Grandjean-Laquerriere, E. Jallot, G. Balossier, P. Frayssinet and M. Guenounou, Biomaterials, 2003, 24, 2739-2747.

241 S. Dey, M. Das and V. K. Balla, Mater. Sci. Eng., C, 2014, 39, 336-339.

242 X. Chen, C. Deng, S. Tang and M. Zhang, Biol. Pharm. Bull., 2007, 30, 128-132.

243 S.-H. Chu, D.-F. Feng, Y.-B. Ma and Z.-Q. Li, Int. J. Nanomed., 2012, 7, 3659-3666.

244 J. Scheel and M. Hermann, Regul. Toxicol. Pharmacol., 2011, 59, 310-323.

245 T. Ding, Y. Xue, H. Lu, Z. Huang and J. Sun, IEEE Trans Nanobioscience, 2012, 11, 336-340.

246 L. Liu, Y. Xiao, Z. Xiao, Z. Wang, C. Li and X. Gong, J. Hyg. Res., 2005, 34, 474-476. 
247 Q. Chen, Y. Xue and J. Sun, J. Appl. Toxicol., 2014, 34, 1256-1264.

248 L. Wang, G. Zhou, H. Liu, X. Niu, J. Han, L. Zheng and Y. Fan, Nanoscale, 2012, 4, 2894-2899.

249 B. Lin, Z. Xi, Y. Zhang and H. Zhang, Weisheng Yanjiu, 2008, 37, 651-653.

250 K. M. de la Harpe, P. P. D. Kondiah, Y. E. Choonara, T. Marimuthu, L. C. du Toit and V. Pillay, Cells, 2019, 8, 1209.

251 Y. Han, X. Wang, H. Dai and S. Li, ACS Appl. Mater. Interfaces, 2012, 4, 4616-4622.

252 I. Nadra, A. R. Boccaccini, P. Philippidis, L. C. Whelan, G. M. McCarthy, D. O. Haskard and R. C. Landis, Atherosclerosis, 2008, 196, 98-105.

253 E. M. Elmowafy, M. Tiboni and M. E. Soliman, J. Pharm. Invest., 2019, 49, 347-380.

254 P. Foroozandeh and A. A. Aziz, Nanoscale Res. Lett., 2018, 13, 339.

255 C. Fornaguera, C. Castells-Sala and S. Borrós, in Cell Biology and Translational Medicine IX, ed. K. Turksen, Advances in Experimental Medicine and Biology, Springer, 2019, vol. 1288, pp. 117-138.

256 N. Voigt, P. Henrich-Noack, S. Kockentiedt, W. Hintz, J. Tomas and B. A. Sabel, J. Nanopart. Res., 2014, 16, 2379.

257 S. Jesus, M. Schmutz, C. Som, G. Borchard, P. Wick and O. Borges, Front. Bioeng. Biotechnol., 2019, 7, 261.

258 N. Grabowski, H. Hillaireau, J. Vergnaud-Gauduchon, V. Nicolas, N. Tsapis, S. Kerdine-Römer and E. Fattal, J. Biomed. Nanotechnol., 2016, 12, 135-146.
259 N. Grabowski, H. Hillaireau, J. Vergnaud, N. Tsapis, M. Pallardy, S. Kerdine-Römer and E. Fattal, Int. J. Pharm., 2015, 482, 75-83.

260 M. Sharma, S. Sharma, V. Sharma, K. Sharma, S. K. Yadav, P. Dwivedi, S. Agrawal, S. K. Paliwal, A. K. Dwivedi, J. P. Maikhuri, G. Gupta, P. R. Mishra and A. K. S. Rawat, Int. J. Biol. Macromol., 2017, 104, 1345-1358.

261 R. P. Singh and P. Ramarao, Toxicol. Sci., 2013, 136, 131-143.

262 K. A. V. Zubris, O. V. Khullar, A. P. Griset, S. Gibbs-Strauss, J. V. Frangioni, Y. L. Colson and M. W. Grinstaff, ChemMedChem, 2010, 5, 1435-1438.

263 O. V. Khullar, A. P. Griset, S. L. Gibbs-Strauss, L. R. Chirieac, K. A. V. Zubris, J. V. Frangioni, M. W. Grinstaff and Y. L. Colson, J. Am. Coll. Surg., 2012, 214, 328-337.

264 R. Löbenberg and J. Kreuter, AIDS Res. Hum. Retroviruses, 1996, 12, 1709-1715.

265 M. A. Radwan, B. T. AlQuadeib, L. Šiller, M. C. Wright and B. Horrocks, Drug Delivery, 2017, 24, 40-50.

266 H. Fasehee, R. Dinarvand, A. Ghavamzadeh, M. EsfandyariManesh, H. Moradian, S. Faghihi and S. H. Ghaffari, J. Nanobiotechnol., 2016, 14, 32.

267 S. Vasanthakumar, H. N. Ahamed and R. N. Saha, Eur. J. Drug Metab. Pharmacokinet., 2015, 40, 137-161.

268 T. C. Moraes Moreira Carraro, C. Altmeyer, N. Maissar Khalil and R. Mara Mainardes, J. Mycol. Med., 2017, 27, 519-529. 